PAPERS IN PHYSICAL OCEANOGRAPHY AND METEOROLOGY

$$
\text { Published by }
$$

MASSACHUSETTS INSTITUTE OF TECHNOLOGY

AND

WOODS HOLE OCEANOGRAPHIC INSTITUTION

VOLUME VI, NO. 3

\title{
ON THE LOCAL DISSIPATION OF NATURAL FOG
}

\author{
BY \\ H. G. HOUGHTON AND W. H. RADFORD
}

CAMBRIDGE AND WOODS HOLE, MASSACHUSETTS

October, 1938 



\section{CONTENTS}

Prefatory Note

by. E. L. Bowles . . . . . . . . . . . . . . . . . 5

Abstract . . . . . . . . . . . . . . . . . . . . . . . . . .

I. On the Possibilities of Fog Dissipation

by H. G. Houghton and W. H. Radford . . . . . . . . . . I3

II. A Method for the Local Dissipation of Natural Fog by Means of Sprayed Calcium Chloride Solution

by H. G. Houghton . . . . . . . . . . . . . . . 27

III. The Design and Operation of a Fog Dissipator Utilizing Sprayed Calcium Chloride Solution

by H. G. Houghton and W. H. Radford . . . . . . . . . . 40

IV. A New Type of Apparatus for the Dissipation of Fog by Means of Fine Hygroscopic Particles

by H. G. Houghton and W. H. Radford . . . . . . . . . . 50 


\section{PREFATORY NOTE}

The following paper treating the subject of local fog dissipation is offered with a twofold purpose. The first is to acquaint the scientific public with theoretical and experimental results of a program of investigation covering many years of directed activity, and the second is to bring added confidence and encouragement to those who are confronted with the critical problem of ameliorating and ultimately surmounting the hazard of fog in navigation by sea and by air.

Fog dissipating has, on the one hand, attracted the attention of crack-pot inventors, and on the other, occupied the minds of sober, able investigators. So it is that there have been visionary grandiose ideas of ridding harbors and airports alike of fog. The scale of operations implied together with the lack of factual data relating to fog as a physical entity have at once fascinated the untrammelled mind of the wild inventor and harassed the mind of the cautious investigator.

The idea of local fog control being thus under a cloud, it is felt necessary, lest the more conservative authorities take umbrage, to preface this paper by an outline of the fog program initiated some ten years ago at the Massachusetts Institute of Technology Round Hill Laboratories and fostered by the Department of Electrical Engineering. It is hoped the reader will see how this research on fog dissipation came quite naturally out of a program not originally directed toward this feature and yet so organized that the significant by-product idea of a successful method for the local dissipation of fog now at least seems an obvious result.

The work which led to the development of a method for the local dispelling of natural fog-one that has been tried on a practical scale-began as a broad program on the subject of fog navigation. Based on the idea that successful navigation under fog conditions and the transmission of intelligence through fog were synonymous, research was undertaken to determine the relative possibilities of signalling through fog by means of acoustic and also electromagnetic waves.

Details included the development of delicate thermocouples capable of responding to the instantaneous excess temperature variations in sound waves of sonic and supersonic frequencies (Johnson and Harris I934) ${ }^{1}$, a theoretical study to determine the upper frequency limit at which radio communication may be effected through rain and fog (Stratton I930), and theoretical and experimental studies of the penetration of fog by light (Stratton and Houghton I931), (Houghton I931).

Confirmation of the results of the theoretical work on the scattering of light by fog naturally depended on a knowledge of fog particle size, on the number of particles to the unit volume, and on the composition of the particles. A search brought out the fact that specific comprehensive data on the sizes and the number of water particles of typical fogs were lacking and means for making these determinations on a sound practical basis also were lacking. Thus work was begun on apparatus for the measurement of fog particle size (Houghton 1932) and on apparatus for the determination of the "liquid water" content of fog.

Within this period, Professor J. A. Stratton, who was then associated with the project, and also Dr. Vannevar Bush with whom the results of the light scattering were discussed, raised the question as to the feasibility of dissipating fog by taking advantage of the selective absorption properties of the fog drops themselves and of the ambient water

\footnotetext{
${ }^{1}$ See list of references at the end of this section.
} 
vapor and carbon-dioxide gas. A brief study of this matter was first made by Dr. W. L. Barrow. Later a more detailed study was made by Mr. H. G. Houghton. Both these men were associated with the Round Hill staff. The results of this study were negative. Because of their background value these results are, however, incorporated in a more complete survey in the first section of the present paper.

The light scattering research led to a chemical analysis of fog water samples which in itself led to the study and development of apparatus for fog water collection. During the course of this work it appeared that hygroscopic nuclei might be utilized for local fog dissipation. The idea was tried on artificial (steam) fog on a laboratory scale and immediately showed such potentialities as a practical means for dissipating fog locally that it was decided to examine the method in detail.

Being already committed to a study of the navigation of aircraft in fog and having already given some thought to the blind-landing problem, it was natural to welcome any means that promised to supplement the radio instrument-landing method and thus to add a much needed factor of safety in that last step of bringing the airplane into contact with the ground and down the runway to a stop.

At this juncture radio-range means had already been in commercial use for some time; runway-localizers and other instrument-approach systems were undergoing rapid developments. Blind-landing systems were already contemplated and, in fact, in actual operation in some places in an experimental way. It therefore seemed reasonable to attack the problem of dispelling enough of the fog over a runway to enable an airplane to make a contact landing or at least to have this alternative as a factor of safety. It was presupposed of course that in the ultimate use of the idea radio means would be available to lead the airplane into this cleared space. In the light of both the blind-landing and fog dissipation developments as we know them today it is felt that this attack on the airplane landing problem has been fully justified.

The knowledge of the physical properties of fog gained through the previous studies referred to above proved invaluable in the preliminary calculations made to determine the feasibility of a full-scale test of the dissipation method. In this initial work and in all subsequent studies as well, there has been a careful emphasis of quantitative methods. The end result, whatever the practical application of local fog dissipation, has been a substantial increase in knowledge of the physical properties of fog and of the means for conveniently determining these properties, as well as a more thorough quantitative knowledge of the transmission of electromagnetic waves through fog, whether they be radio, light, or long infrared. ${ }^{2}$

A recent grant from the Humane Society of the Commonwealth of Massachusetts has now fortunately enabled us to continue the study of the applicability of infrared radiant energy to fog navigation.

On behalf of the Institute, it is with gratitude that I record here the sources of assistance which have made the work possible.

We owe much to the foresight of the late Colonel E. H. R. Green who in I 925 placed at the Institute's disposal the unusual facilities of his Round Hill estate ${ }^{3}$ on which our

\footnotetext{
2 In addition to the papers which have already appeared, one entitled "On the Measurement of Drop Size and Liquid Water Content in Fogs and Clouds" by H. G. Houghton and W. H. Radford is to be published soon as Vol. VI, No. 4 of this series.

Papers dealing with the following subjects are now in the final stages of preparation:

"Transmission of Visible Radiations Through Natural Fog"

"Transmission of Infrared Radiations Through Natural Fog"

${ }^{3}$ Round Hill is at South Dartmouth, Massachusetts on the west shore of Buzzards Bay, about six miles south of the City of New Bedford.
} 
fog and field-radio laboratories have been established. He aided us by numerous financial and other grants and for many years, when he was able to be active, took a keen personal interest in the work.

Through the courtesy of his sister, Mrs. H. Sylvia A. H. G. Wilks, we have been able to continue work at Round Hill since Colonel Green's untimely death and thus to carry to completion our several projects.

It was through Mr. Godfrey Cabot that we were able to engage W. H. Radford and start him on light transmission and fog water content measurement work. Aid from the American Philosophical Society in the form of a grant from the Penrose Fund made it possible to set up apparatus for the first tests on the hygroscopic particle method of local fog dissipation. Support of the Bureau of Aeronautics, Navy Department, the U. S. Army Air Corps, and the Bureau of Air Commerce of the Department of Commerce enabled us to carry on the research a considerable period after the first practical outdoor tests and to perfect details of apparatus and method.

We are grateful to the Michigan Alkali Company and the Columbia Alkali Company for the donation of calcium chloride, to the Dow Chemical Company for valuable physical and chemical data on calcium chloride and also for the contribution of large quantities of specially-graded calcium chloride powder, and to the Edison Electric Illuminating Company of Boston for the loan of a large power transformer for use in many of the dissipation tests.

The success of the fog dissipation project is due in the main to the deep interest and unremitting efforts of my colleagues, H. G. Houghton and W. H. Radford, who have responded enthusiastically and nobly in the face of the many odds incidental to a research program of this character.

Finally it is my pleasure to acknowledge the assistance of others of my colleagues at Technology. Among these are Professor Dugald C. Jackson, head of the Department of Electrical Engineering (now emeritus) whose encouragement, vision, and active support have been invaluable, Dean Vannevar Bush, Dr. Jerome Hunsaker, Professor C. -G. Rossby, and President K. T. Compton who has so often come to the assistance of the project.

EDward L. Bowles

Director, Round Hill Research Division, Professor of Electrical Communications, Department of Electrical Engineering Massachusetts Institute of Technology.

\section{REFERENCES}

Houghton, H. G.,

193 I The transmission of visible light through fog, Physical Review, 38, I 52.

1932 The size and size distribution of fog particles, Physics, 2, 467 .

Johnson, E. A. AND Harris, L.

I934 The technique of sputtering sensitive thermocouples, Rev. Sci. Instr., 5, I 53.

Stratton, J. A.

1930 The effect of rain and fog on the propagation of very short radio waves, Proc. I. R. E., I8, I064.

Stratton, J. A., and Houghton, H. G.

I93 I A theoretical investigation of the transmission of light through fog, Physical Review, 38, I 59. 
•

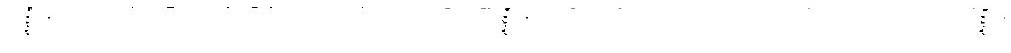




\section{ACKNOWLEDGMENT}

The authors take this opportunity to express their gratitude to Professor Edward L. Bowles, Director of the Round Hill Research Division. Without his enthusiastic encouragement, wise and friendly counsel, foresight, tenacity of purpose and indefatigable efforts in obtaining support and recognition for this work it could not have been carried through to its logical conclusion.

H. G. Houghton

W. H. RADFORD 


\begin{abstract}
It is submitted that the hazards of landing aircraft in fog could be greatly reduced by providing relatively small clearings into which approaching planes could be safely guided by radio or other navigational aids which are now available. The same general method might also be used to facilitate the entrance of ships into fog-bound harbors or docks.

In the first section of this paper the properties of fog which are of importance in the discussion of methods of fog dissipation are summarized on the basis of measurements made at Round Hill. The minimum dimensions of a cleared space of useful size are taken as 500 to I000 meters long, 30 to 50 meters wide and ro to 20 meters high. From extensive investigations at Round Hill it is known that in order to maintain a clearing of this size under typical wind conditions, fog must be cleared at a minimum rate of about 2000 cubic meters per second. This figure is used for all subsequent computations.

It is pointed out that the known methods of fog dissipation can be divided into two general classifications: (I) those in which the fog particles. are physically removed from the air, and (2) those in which the particles are evaporated in the air. Numerous specific methods are then described and critically examined with respect to their ability to provide cleared air at a rate of 2000 cubic meters per second in a reasonably practical manner. The more important methods considered involve the use of intense sound fields, charged or uncharged falling particles, electrical precipitation, mechanical precipitation, evaporation by heating and evaporation induced by the condensation of atmospheric water vapor on hygroscopic particles. It is concluded that the evaporation methods as a class are superior to the physical removal methods because they lower the relative humidity of the cleared air and thereby greatly reduce the limiting effects of atmospheric turbulence which act to "fill in" the cleared space. The method involving the condensation of water vapor by means of calcium chloride is chosen as being probably the most practical of the fog dissipation methods considered.

The second section of the paper presents a detailed examination of one application of the calcium chloride method of fog dissipation. In this method drops of a saturated solution of calcium chloride are released above the volume of fog which is to be cleared. These hygroscopic drops, which are large enough to fall fairly rapidly, condense a sufficient quantity of water vapor from the air through which they descend to effect the evaporation of the fog particles.

The investigation of this method of fog dissipation is divided into three parts. The first part deals with the determination of the relative humidity required to cause the evaporation of the fog drops as a function of the time of evaporation and the size of the fog drops. The second part is concerned with the rate of condensation of water vapor on drops of calcium chloride solution as a function of the drop size and concentration. In the third part the criteria for the selection of the optimum size of the solution drops are presented and the development of spray nozzles capable of forming drops of approximately the desired size is described briefly. Finally, the quantity of calcium chloride solution required for the dissipation of fog under typical conditions is computed. It is found that, with the best available spray nozzles, fog can be dissipated at a rate of 2000 cubic meters per second (sufficient to maintain a cleared space of useful size under typical conditions) by spraying from 4 to 5 liters of saturated solution per second. It is concluded that the method is practicable on the scale proposed.

The third section of the paper is an account of the design and successful operation of a fullsized experimental fog dissipator operating according to the method described in the second section. The major considerations which influenced the determination of the size and spraying capacity of the apparatus are summarized and the essential features of the actual installation are described. The test procedure is outlined and the average results of eight successful tests conducted during a period of two and one-half years are indicated. The tests were made at air temperatures ranging from $4^{\circ}$ to $20^{\circ} \mathrm{C}$ and at wind velocities up to 7 meters per second. The clearings
\end{abstract}


formed were usually from 500 to 700 meters long, 30 to 50 meters wide and 15 to 20 meters high. After the installation of an improved type of spray nozzle clearings of the same size were maintained by spraying only 5 liters of saturated calcium chloride solution per second. The data obtained in two typical fog dissipation tests are presented in detail. It is found that the experimental results are in excellent agreement with the computations presented in the second section of the paper. It is concluded that the local dissipation of natural fog by means of sprayed calcium chloride is entirely feasible. Certain practical disadvantages of the experimental installation are discussed and a new type of apparatus which has recently been constructed to overcome some of these limitations is briefly described. Methods for practically eliminating the corrosive action of the calcium chloride solution are also noted.

The fourth and final section of the paper describes a new type of apparatus in which the general method of fog dissipation by means of hygroscopic particles is applied in a different manner. By substituting finely-divided calcium chloride powder for the relatively coarse spray it is possible to confine the hygroscopic material entirely within the dissipating apparatus which is constructed in the form of a short tunnel. The spent hygroscopic material is removed from suspension by means of a special eliminator and only cleared and dehumidified air is discharged. A powerful engine-driven blower facilitates proper distribution of the cleared air under all wind conditions. The advantages of this type of apparatus in comparison with that described in the third section are: the absence of an external spray of calcium chloride, its independence of wind velocity over a considerable range, and its smaller size which reduces the obstruction hazard and permits it to be made mobile.

From the results of tests with the spray-type fog dissipator it was known that the new apparatus should be capable of reducing the relative humidity to $90 \%$ in 2000 cubic meters of fog per second in order to maintain a clearing of useful dimensions under typical conditions. A unit of excessive size would be required to handle this quantity of air. However, it is possible to remove a sufficient quantity of water vapor from a fraction of the air so that the required relative humidity of $90 \%$ can be produced in the total volume of air by proper admixture of the dried portion.

A commercial calcium chloride powder was selected as the most suitable hygroscopic material and computations were made to determine the quantity of powder required and the time necessary for it to act. In order to check these computations, which involved several simplifying assumptions, and also to develop the essential features of the proposed apparatus, a working model was set up outdoors. Results from the tests with the model are in fairly good agreement with the computations. It was determined that the lowest practical exit relative humidity is about $50 \%$. Since a relative humidity of $90 \%$ suffices for the dissipation of fog only one-fifth of the total volume of air to be cleared need be handled by the apparatus on this basis.

The eliminator which mechanically removes the spent calcium chloride particles from the dehumidified air is an important part of the apparatus. After numerous tests on typical eliminators it was found necessary to develop a new type which would be effective at the required high flow velocities.

The important problem of properly distributing the dried air was studied with the aid of a large mobile blower unit. It was concluded that, although it would be preferable to employ a number of appropriately spaced discharge ports when possible, a satisfactory distribution could be effected from a single large opening by using a discharge velocity of from 20 to 30 meters per second.

Preliminary designs for two units of the new type are presented to show that the size, weight, blower power requirements and quantity of calcium chloride required for apparatus capable of maintaining cleared spaces of useful size are not unreasonable. 


\title{
I. ON THE POSSIBILITIES OF FOG DISSIPATION
}

\author{
By H. G. HOUGHTON ${ }^{1}$ and W. H. RADFORD \\ Round Hill Research Division, Department of Electrical Engineering \\ Massachusetts Institute of Technology
}

\section{INTRODUCTION}

In this age of high-speed transportation the hazards of navigation in fog have become increasingly serious. The possibilities of solving this problem by dissipating the fog have frequently been considered and even experimentally investigated by various persons. However, it appears that little sound scientific work has been done on the problem, doubtless because it has been apparent that the clearing of great volumes of fog, such as the entire regions over harbors or airports, would usually require prohibitive amounts of energy and apparatus.

Recent developments in navigational methods and instruments definitely suggest that fog clearings of an economically producible size should now have considerable practical value. For example, radio aids have become available which are apparently capable of safely guiding aircraft into a region reasonably close to the desired landing area. Although many experimental "blind landings" have been made using equipment of this type, the actual contact with the ground and the subsequent handling of the aircraft on the ground still present such serious difficulties and dangers that the method cannot as yet be used commercially. It is believed that if a fog clearing of modest size were provided, the hazards would be largely eliminated from the final stages of the landing, since after the radio aid had guided the approaching plane into the clearing, the ground and any nearby obstructions would be plainly visible to the pilot or co-pilot and a safe, normal landing could be made.

A consideration of the precision with which an airplane can be guided by available radio aids and of the space required for landing suggests that the fog clearing should have for its minimum dimensions a length of from 500 to 1000 meters, a width of from 30 to 50 meters, and a height of from Io to 20 meters. In fogs of great depth relatively precise radio aids would be required to guide the airplane safely into the clearing, but in the case of the shallow radiation fogs prevalent during the night and early morning hours in some sections, less accurate guidance would be necessary since the clearing would be plainly visible from aloft.

It is conceivable that clearings of the size described, or ones somewhat larger, might also be used, in conjunction with appropriate navigational aids, to facilitate the entrance of ships into fog-bound harbors or docks.

\section{Important Properties of Fog}

Natural fog is an aerosol consisting of a suspension of small water drops in an atmosphere wherein the water vapor pressure is normally saturated with respect to the fog particles. Measurements made in numerous typical sea fogs which have occurred at Round Hill ${ }^{2}$ in recent years show that there are usually from I to 10 fog particles per cc of air. Invariably there is a considerable range of particle sizes, and while in different

1 Now in Meteorological Division, Department of Aeronautical Engineering, Massachusetts Institute of Technology.

2 Round Hill, the estate of the late Colonel E. H. R. Green, is located on Buzzards Bay about six miles south of New Bedford, Mass. 
fogs the size distributions are not exactly alike, they are always continuous. Usually the drops are between 2 and 100 microns in diameter and most of the liquid fog water is in the form of drops having diameters between 20 and 50 microns. The maximum quantity of liquid water ever actually observed was about $0.3 \mathrm{~g}$ per cubic meter of fog corresponding to a daylight visibility of approximately 125 meters (Houghton I932), (Houghton and Radford I938). ${ }^{3}$ Chemical analyses of numerous samples of fog water indicate that although it always contains dissolved salts, the concentration is usually so low that, for the purposes of fog dissipation, fog particles may be regarded as practically pure water.

The foregoing summary of fog characteristics applies strictly only to the fogs examined at Round Hill, but the numerical values given are probably typical for sea fogs and many country fogs. However, fogs formed in or near large industrial centers may have quite different properties. Such fogs are of ten admixed with considerable smoke which cannot, in general, be dissipated in the same manner as fog. Due to the presence of great numbers of hygroscopic nuclei (provided by combustion products) it is possible that some city fogs comprise very many relatively small particles. The probable high concentration of dissolved hygroscopic matter in such fogs would render them more difficult to evaporate than the relatively cleaner sea fogs which cannot persist in an atmosphere having a relative humidity appreciably less than $100 \%$. In the absence of specific quantitative data on typical city fogs, the present discussion of fog dissipation will assume fogs having physical characteristics similar to those observed at Round Hill.

Fogs may vary in depth from a meter or less in the case of extremely shallow radiation fogs to a thousand meters or more in the case of advection fogs. Most persistent and extensive fogs are so deep that it would be impracticable to provide clearings ranging throughout their height.

In a consideration of methods of fog dissipation the wind velocity accompanying the fog is a very important factor. It not only determines the quantity of fog which must be dealt with per unit of time in order to maintain a clearing of specified size, but it also affects the shape and persistence of the clearing and the arrangement of the necessary apparatus. Fog is rarely found in absolutely calm air, the wind velocity usually being from I to Io meters per second. When accompanied by relatively strong winds (greater than about 3 meters per second), which are ordinarily quite constant in direction, a suitable clearing can be formed by dissipating all of the fog passing through an area perpendicular to the wind direction. The clearing will then appear in the form of a lane or tunnel extending down-wind from the apparatus. In the case of light and variable winds it becomes necessary to apply the fog dispersing agent or material throughout the volume of the desired clearing. In either case, the extent or persistence of the clearing produced will be limited by the turbulent diffusion of fog into the cleared space from the sides and top. Since this is an edge effect it becomes less important as the initial size of the clearing is increased.

\section{General Requirements for Fog Dissipation}

Calculations and experiments described in considerable detail in the second and third sections of this paper indicate that in order to maintain a clearing of useful size under typical wind conditions, fog must be cleared at a minimum rate of about $2000 \mathrm{~m}^{3} / \mathrm{sec}$. It is assumed that the clearing formed is to be used in conjunction with an appropriate radio or other suitable navigational aid, as suggested in the Introduction. With fogs

\footnotetext{
${ }^{3}$ See list of references at the end of this section.
} 
accompanied by wind velocities exceeding approximately $8 \mathrm{~m} / \mathrm{sec}$ it is probable that a greater clearing rate would be necessary.

However, for the purposes of critically examining and comparing the various methods of fog dissipation, it will be assumed throughout the remainder of the paper that fog is to be cleared at the rate of $2000 \mathrm{~m}^{3} / \mathrm{sec}$. When illustrative computations require the assumption of a definite wind velocity, the value of $5 \mathrm{~m} / \mathrm{sec}$ will be used, and at the same time it will be assumed that the clearing is to have initially a height of Io meters and a width of 40 meters.

Furthermore, it will be considered desirable for the fog dissipation apparatus to be operable under all probable wind conditions, including those approaching a calm. The necessary equipment should not constitute a navigational hazard and if possible should be mobile. Obviously, it should also be relatively inexpensive and its operation should have no harmful effects on property or persons.

\section{Classification of Fog Dissipation Methods}

In order to dissipate fog it is necessary to eliminate the fog particles from the atmosphere either by a process of physical removal or by a process of evaporation. The evaporation methods of fog dissipation may be divided into two groups:

(I) those in which the fog is evaporated solely by the application of heat, and

(2) those whereby the vapor pressure difference necessary for evaporation is obtained partly, if not wholly, by removing a portion of the atmospheric water vapor.

The principal physical removal methods may also be divided into two groups:

(I) those in which the fog drops are removed by gravity after coalescence, or after collection on larger particles introduced for the purpose, and

(2) those methods wherein the individual fog droplets are precipitated onto suitable large surfaces from which the collected water can be drained or otherwise removed.

\section{Physical Removal Methods}

One suggested method of fog dissipation which may be considered as belonging to the physical removal class involves the replacement of fog with clear air drawn down from above by means of powerful blowers. It might appear that this could be accomplished over an airport, for example, by rapidly draining the surface air through underground ducts leading to a remote discharge opening. However, owing to the fact that the vertical temperature gradient in fog is always less than the'adiabatic (frequently there is a marked inversion) it would be very difficult to induce the clear upper air to flow down to the ground level. The tendency would be, rather, for the unwanted fog to flow in from the sides. Even in shallow radiation fogs, where conditions would be most favorable to this method, tremendous quantities of air would have to be handled to obtain a reasonable clearing and in general the power requirements would be inordinately large. With advection fogs, owing to their higher wind velocities and much greater depths, the method is even more impracticable. Such apparatus could not be made mobile and the cost of its installation would be excessive. It must be concluded that the method does not merit serious consideration. ${ }^{4}$

In those physical removal methods of fog dissipation whereby the ultimate elimination of the particles is accomplished by gravity, the first step must be either the coales-

${ }^{4}$ The folly of attempting to apply this method on a large scale is discussed in (Humphreys 1926) and (Aero. Res. Reports I921). 
cence of the particles to form drops of sufficient size to fall rapidly to the ground, or the collection of the fog droplets on rapidly falling larger particles introduced for the purpose. In a hypothetical case the coalescence of a large number of fog particles might be effected by in troducing forces which would cause all of the particles within a given radius to move to a common center thus forming a single large drop which would then rapidly fall to the ground. The energy required to do this can be readily calculated from the size distribution and number concentration data for the fog. The amount of energy is small in comparison, for example, with that required to eliminate the same droplets by evaporation. However, since there is no known method of efficiently applying the forces necessary, these energy computations are of little practical significance.

On more than one occasion it has been suggested that coalescence and consequent gravitational removal of fog particles might be effected simply by subjecting the fog to an intense electrostatic field. Although fog, like any aerosol, can be precipitated by electrical methods when properly applied, there is no reason why natural fog particles, which normally carry only very small charges, should be expected to coalesce simply because they are subjected to a strong electric field. The one possible method by which actual coalescence of fog particles might be effected involves the use of high intensity sound fields. This method will be considered presently.

Fog drops can be removed from suspension by large, rapidly falling particles which are supplied either with strong electric charges, or in sufficient numbers to mechanically collect or entrain all of the fog droplets.

The methods of eliminating fog by causing the particles to be deposited on larger surfaces from which the collected water can drain are all, fundamentally, extensions or adaptations of the well known commercial methods for cleaning large volumes of gases. Thus it is conceivable that the familiar Cottrell method of electrostatic precipitation might be applied, or that the fog might be cleared by passing it through an appropriate array of baffles as is done in air washers and gas scrubbers. Each of the possibilities mentioned will now be reviewed to determine the extent of its applicability in the practical dissipation of natural fog.

\section{On the Use of Intense Sound Fields}

The use of high intensity sound fields for the dissipation of fog is an interesting possibility suggested by the recent work of Andrade (1936), Brandt and Hiedemann (1936), Brandt, Freund and Hiedemann (1936), Brandt (1936, 1937), and Brandt, Freund and Hiedemann (1937), and others on the precipitation of smoke and dust by means of standing sound waves of sonic or supersonic frequencies. The particle sizes and separations are much larger for natural fog than for smoke or dust and since no results of experiments on the sonic precipitation of aerosols similar to natural fog are available, it is difficult to estimate the applicability of the method to fog dissipation. Moreover, the general theory of sonic precipitation is still in the formative stage. Owing to the complexity of the physical phenomena involved, both theoretical and experimental examination of the process are quite difficult. However, it is agreed that there are two effects which contribute to the coagulation of the suspended particles. One arises from differences in amplitudes of the vibrating particles. This is of relatively greater importance at lower frequencies. The other effect is due to the hydrodynamical forces of attraction, and appears to be more important at higher frequencies.

Brandt, Freund and Hiedemann (1936) have found that when a non-homogeneous 
aerosol is subjected to stationary sound waves of proper frequency, the individual particles oscillate with different amplitudes. The smaller particles vibrate with amplitudes substantially equal to that of the air, intermediate particles with lesser amplitudes, and particles larger than a certain limiting size have practically no motion. The vibration amplitude of a particular particle is a function of its size and density, the air viscosity and the frequency and intensity of the sound. If the sound frequency is appropriate, and the intensity sufficient, particles of unlike size will be caused to collide, resulting in coalescence and consequent precipitation of the aerosol.

For natural fog the most effective frequency is of the order of I000 cycles per second. Evidently, if collisions are to result, the amplitude of vibration of the smaller particles, which is approximately equal to the amplitude of the sound field, must be of the same order of magnitude as the average separation between the fog drops. For large particle sea fogs the average distance between drops is of the order of 5 millimeters. ${ }^{5}$ Thus an unreasonably intense sound field would be required. The necessity of providing standing waves is another practical difficulty.

The hydrodynamical force of attraction, which acts on spheres at rest in a vibrating medium, may also contribute to the coagulation of particles suspended in a sound field. This force is attractive when the line of centers of the drops is normal to the direction of motion of the fluid and repulsive when it is parallel. The force between two spheres varies directly as the square of the (maximum) velocity of the vibrating fluid and the sixth power of the drop radius, and inversely as the fourth power of the distance between drop centers (Andrade 1936). Although hydrodynamical forces might in a general way account for the observed coagulation of smoke when subjected to stationary supersonic waves, if the formulae are applied to natural fog it is found that, due to the relatively wide spacing of the drops, unreasonably high air velocities must be provided to induce coalescence at a sufficiently rapid rate. This requires a large value for the frequencyamplitude product of the sound wave and a correspondingly large sound energy.

Owing to the present unsatisfactory state of the knowledge of sonic and supersonic precipitation, it is practically impossible to estimate the power that would be required for large scale precipitation of fog by such methods. An accurate estimate will be possible only after considerably more experimental data are available. However, from the present state of development of the method it does not appear that it would ever be useful for fog dissipation on a practical scale.

\section{On the Use of Charged Particles}

Because of the appreciable velocity of fall of natural fog drops (O.OI to $26 \mathrm{~cm} / \mathrm{sec}$ ), their comparatively great separations $(0.3$ to $1.0 \mathrm{~cm})$, their lack of large electrical charge, and the small value of the maximum charge which can be carried by particles small enough to remain in suspension, it is not possible to coagulate natural fog by introducing a number of small charged nuclei. However, charged particles can be advantageously used by employing ones considerably larger than the fog droplets so that they can bear greater charges and so that, in falling through the fog, they will attract a number of fog particles, carrying these to the ground. This physical removal method of fog dissipation has been applied with varying degrees of success by dropping charged sand or water drops above clouds or fogs.

\footnotetext{
5 Corresponding to 8 drops/cc-a typical value for dense sea fogs as observed at Round Hill.
} 
Humphreys has shown ${ }^{6}$ that a spherical grain of sand Ioo microns in diameter and carrying a charge of $\mathrm{I} / \mathrm{5}^{\mathrm{I}}$ esu (the theoretical maximum in air) will, falling in still air, capture all fog particles (irrespective of size) that it passes within a center distance of about $0.019 \mathrm{~cm}$. That is, a single particle in falling will clear a vertical column $0.019 \mathrm{~cm}$ in radius. Assuming that the method could be used to clear $2000 \mathrm{~m}^{3} / \mathrm{sec}$ of fog to a height of Io meters, the required weight of sand is about $2.5 \mathrm{~kg} / \mathrm{sec}$. In a practical case the particles would not be spherical nor of the same size; they could not be distributed in a perfectly uniform manner nor would they all carry the theoretical maximum charge, due to the limiting effects of their irregular shapes and sharp edges. Therefore, the weight of sand actually required would probably be several times the value computed.

Nevertheless the necessary quantity of sand does not appear to be unreasonably large, particularly in view of its cheapness. If the sand could be properly charged and distributed the method might be workable on the scale proposed. Similarly it might be possible to use charged water drops of about the same size. The serious problem in the utilization of charged water spray would be in providing droplets of sufficiently uniform diameter.

\section{On the Mechanical Sweeping Action of Falling Particles}

The results of experimental studies of the collection of fog droplets on small uncharged wires suggest that full-scale precipitation of fog might be accomplished by dropping through it enough rela tively large particles to effectively cover the area to be cleared. In order to keep the required weight of material at a minimum it would be desirable to utilize the smallest particles having a sufficiently rapid rate of fall. If water were used droplets 100 microns in diameter (falling at the approximate rate of $26 \mathrm{~cm} / \mathrm{sec}$ ) would probably be satisfactory. The quantity of water theoretically required to clear 2000 $\mathrm{m}^{3} / \mathrm{sec}$ to a depth of Io meters would then be $\mathrm{I} 3.3 \mathrm{~kg} / \mathrm{sec}$. In a practical case this quantity would probably have to be at least doubled to compensate for the unavoidable range of drop sizes and the impossibility of effecting an ideal distribution.

Unfortunately, in discharging this amount of water from any of the usual types of nozzles there would be formed a very great number of extremely small drops which would probably constitute a secondary fog fully as dense and as objectionable as the original natural fog. There is, however, an excellent possibility that this serious defect in the method might be largely overcome by using a new type of spray nozzle developed at this laboratory.

Instead of water spray, uncharged particles of sand or other convenient material could obviously be used. Although this method of precipitating natural fog, like the charged particle method, could probably be made to operate on the scale proposed, there are other methods which seem decidedly more practicable.

\section{Electrical Precipitation of Fog}

Natural fog has no properties which prevent its electrical precipitation by the well known Cottrell method, which has long been used for removing smoke, dust and fumes from industrial gases. In its simplest form, an electrical precipitator consists of a cylindrical metal tube having an insulated axial wire which is maintained at a high (usually negative) potential with respect to the tube. The voltage is sufficient to produce vigorous corona discharge in the vicinity of the wire. The gas containing the particles to be pre-

\footnotetext{
${ }^{6}$ See p. 64 of (Humphreys I926).
} 
cipitated flows slowly through the tube. The precipitating action comprises two distinct phases, the first being an accumulation on the suspended particles of ions (and electrons) liberated in the corona region. After being charged the particles are driven to the outer electrode by the action of the electrostatic field and are thus separated from the gas.

With particles the size of natural fog droplets the maximum charge acquired, according to Ladenburg (1930) is given by:

$$
n e=E_{0} r^{2}\left(\mathrm{I}+2 \frac{k-\mathrm{I}}{k+\mathrm{I}}\right)
$$

where $n$ is the number of electrons, $e$ the electronic charge, $E_{0}$ the charging field intensity, $r$ the particle radius, and $k$ the dielectric constant. A particle with a charge $(n e)$ in a precipitating field of intensity $E$ will be acted upon by a force $(n e E)$. With fog droplets the air resistance is given by Stokes' Law, so that the velocity of drift due to the field is:

$$
V_{d}=\frac{n e E}{6 \pi \mu r}
$$

where $\mu$ is the coefficient of viscosity for air.

In applying the method to the dissipation of natural fog it would probably be desirable to use separate ionizing units and parallel collecting plates as described by Penney (1937). A suitable arrangement might comprise a series of flat horizontal or vertical equally spaced plates, alternate ones being maintained at a high unidirectional potential with respect to the intermediate ones which could be grounded. This plate array could be mounted along the windward side of the desired clearing, being so oriented that the wind would blow freely through it without suffering appreciable resistance or change in direction. Ionizing electrodes would be provided on the inlet side so that fog particles entering the uniform precipitating field between the plates would be well charged.

In order to obtain a satisfactory clearing with this arrangement, it would be necessary to remove all particles larger than about to microns in diameter. From discussions in the paper by Ladenburg (1930) and the one by Penney (1937) it appears that for the apparatus proposed it is reasonable to assume $E_{0}=10$ and $E=20$ statvolts $/ \mathrm{cm}$. Considering the fog particles to be pure water $(k=8 \mathrm{I})$ and taking the viscosity of air as $\mu=178 \times 10^{-6}$ poises, from equations (I) and (2) the theoretical maximum value of the transverse velocity of a 10 micron particle is $V_{d}=88 \mathrm{~cm} / \mathrm{sec}$. Since the flow through the precipitator would equal the wind velocity (assumed to be $5 \mathrm{~m} / \mathrm{sec}$ ), it is apparent that in order to insure capture of all particles ro or more microns in diameter, the length of the apparatus in the direction of flow must be at least $(500 / 88=5.6)$ times the plate separation.

Under the assumed typical conditions the fog would be accompanied by a wind of 5 $\mathrm{m} / \mathrm{sec}$ and it would be necessary to clear $2000 \mathrm{~m}^{3} / \mathrm{sec}$ to a height of Io meters. In an extreme case the precipitator might have only one horizontal plate mounted Io meters above the ground which would serve as the other required electrode. According to the foregoing calculations the length of this plate in the direction of flow would have to be 56 meters. To obtain the value of $E$ assumed, the potential difference between the elevated plate and ground would have to be six million volts. Such an arrangement would be impractical for many reasons, an important one being that atmospheric turbulence would seriously interfere with the precipitation process, greatly reducing the volume of air actually cleared. A better arrangement would be one using a number of shorter and less widely spaced plates. 
In any case the required structure would be large and cumbersome and would constitute a dangerous obstruction if installed at an airport. Owing to its size it might be difficult to make such a unit portable. In order for the precipitator to be useful in relatively calm fog, means would have to be provided either for moving it as a unit through the air to be cleared or for forcing the air through it.

It appears that the sole advantage of the electrostatic precipitator method of fog dissipation is its modest power requirement. Available data on large commercial precipitators indicate that the energy consumed is usually less than two kilowatt-hours per million cubic feet of gas cleaned. Assuming about the same efficiency, the power required to operate the proposed fog dissipating unit would be only $500 \mathrm{kw}$. However, this advantage would probably be more than offset by the high first cost of the required equipment and the practical objections to its size. It must be concluded therefore that although the electrical precipitation method might be used, in its present state of development it can hardly be considered adaptable to the requirements for dissipating natural fog on a practical scale.

\section{Mechanical Precipitation of Fog}

The one other method to be considered for physically removing fog droplets from the atmosphere involves the use of a structure which causes fog flowing through it to be deflected a number of times in such fashion that the kinetic energy of the droplets forces them to be deposited upon the deflecting members. Devices of this type commonly known as "eliminators" are extensively used for mechanically separating particles of all sorts from moving gas streams. In an application to fog dissipation, such apparatus might be mounted along the windward side of the desired clearing. Owing to its very nature, any device of this type would offer considerable resistance to the passage of air through it. Therefore it would be found that if the wind alone were used as the driving force, a large portion of the fog would be deflected around the edges of the unit, mixing with the clear air which had passed through it. Thus only partially cleared air would be obtained.

This difficulty could be avoided by using blowers to move the fog through the apparatus. This arrangement would have the added advantage of making the device operable in the absence of appreciable wind. Recent experimental data ${ }^{7}$ indicate that an eliminator suitable for this application would have, at an air velocity of $5 \mathrm{~m} / \mathrm{sec}$, a resistance corresponding to a static pressure drop of only $0.76 \mathrm{~cm}$ of water. The power required to move $2000 \mathrm{~m}^{3}$ of air per second through such an eliminator is only about 200 $\mathrm{hp}$ or $\mathrm{I} 5 \mathrm{Kw}$, neglecting the blower efficiency and incidental losses. Although this is a modest amount of power, a very elaborate structure incorporating a large number of blowers would undoubtedly be required. The method thus has practical disadvantages similar to those of the electrical precipitation method previously discussed. It is possible, of course, that the size of the apparatus could be reduced by increasing the air velocity, but modification in this direction would be seriously limited by the fact that the power required to move a given quantity of air through such a device is proportional to the square of the air velocity. A high discharge velocity would produce severe turbulent mixing which, in this case, would seriously restrict the extent of the clearing. It must be concluded that although possible, the method is hardly practicable.

${ }^{7}$ See Section IV. 


\section{Evaporation Methods}

In all evaporation methods of fog dissipation sufficient energy must obviously be provided to furnish the heat of vaporization of the liquid fog particles. In addition, it is always necessary to supply a much larger amount of energy in order to create the vapor pressure difference essential for satisfactorily rapid evaporation of the fog particles. From considerations which are fully discussed in the next section, it has been determined that, in effect, the relative humidity of the atmosphere should be reduced to at least $90 \%$ to insure a sufficiently rapid evaporation rate. (At an ambient temperature of $20^{\circ} \mathrm{C}$ and a relative humidity of $90 \%$, all fog particles smaller than 50 microns in diameter will completely evaporate within about 25 seconds).

To reduce the relative humidity of a cubic meter of air initially saturated at $20^{\circ} \mathrm{C}$ to $90 \%$ requires an energy of 520 calories, corresponding to an air temperature rise of $1.8^{\circ} \mathrm{C}$. This energy necessarily includes the heat of vaporization of the fog water, which would equal II 7 calories for a typical initial liquid water content of $0.2 \mathrm{gm} / \mathrm{m}^{3}$. Thus in this case only $22.5 \%$ of the required energy would actually be consumed in evaporating the fog particles. Evidently, the power required to clear $2000 \mathrm{~m}^{3}$ of fog per second is about I.04 $\times \mathrm{IO}^{6} \mathrm{cal} / \mathrm{sec}$, or $4360 \mathrm{kw}$.

This power must be available in all but one of the possible evaporation methods. This exception, which will be discussed presently, is the hypothetical case wherein the necessary vapor pressure difference is obtained by applying the heat directly to the suspended fog droplets.

With the exception just noted, all evaporation methods of fog dissipation have an important advantage over the physical removal methods owing to the fact that the cleared air initially has a reduced humidity. For this reason, when fog is carried in to the clearing from the sides and top by atmospheric turbulence, it will be evaporated until such time as the relative humidity approaches $100 \%$. In fogs accompanied by winds of average velocity it is believed, by virtue of this effect, that the clearing produced by an evaporative method will be at least twice as large as one formed by a physical removal method acting upon the same quantity of fog. On the other hand, it should be noted that the physical removal methods act more quickly than the evaporation methods in which from 5 to 30 seconds may be required for complete evaporation of the fog particles.

\section{Evaporation by Heating}

Probably the simplest method of supplying the energy required for the evaporative dissipation of fog consists in the direct application of heat to the fog by means of an appropriate array of either open fires or electrically or steam-heated grids. In any case the distribution of the energy throughout the space to be cleared must be highly uniform, not only to keep the amount required at a minimum by avoiding unnecessary heating, but also to prevent the formation of convection currents which would carry the cleared and heated air aloft and draw additional fog in from the sides. In using a method of this type in fogs accompanied by moderate winds, the apparatus would have to apply the heat uniformly over the windward side of the desired clearing. In the case of relatively stagnant fog it might be necessary to provide horizontal or even three-dimensional distribution. In any event, owing to the distribution requirement, it appears that the necessary equipment would be large and cumbersome and would probably constitute a dangerous obstruction at an airport. 
Nevertheless, it is an interesting fact that if fuel oil could be burned in the atmosphere by some method which would insure uniform heating, the cost to clear 2000 cubic meters of fog per second would be comparatively little. Thus if the oil used had a combustion heat of $\mathrm{I} 0,500 \mathrm{cal} / \mathrm{gm}$, a specific gravity of 0.9 , and cost $\mathrm{I} .6 \mathrm{cents} / \mathrm{liter}$, only 49.5 milligrams would need be burned per cubic meter of air to provide the energy of $520 \mathrm{cal}-$ ories required for satisfactory evaporation of the fog. To clear $2000 \mathrm{~m}^{3} / \mathrm{sec}$ would evidently require only 99 grams of oil per second, costing about O.I 8 cent per second.

Unfortunately, in a practical case the heating would not be uniform, so the burning of several times as much fuel would undoubtedly be necessary. It is understood that a method of this sort, using a distributed array of small oil burners, is being experimented with in England, but no information about the details of the apparatus or results obtained with it in fog are yet available.

Another possible method of dissipating fog by heating the atmosphere involves the use of calcium oxide (quicklime) which readily reacts chemically with atmospheric carbon dioxide and with water vapor in accordance with the equations:

$$
\begin{aligned}
& \mathrm{CaO}+\mathrm{CO}_{2}=\mathrm{CaCO}_{3}+43,350 \text { calories }^{8} \\
& \mathrm{CaO}+\mathrm{H}_{2} \mathrm{O}=\mathrm{Ca}(\mathrm{OH})_{2}+26,500 \text { calories. }
\end{aligned}
$$

Conceivably, particles of $\mathrm{CaO}$ might be evenly distributed throughout the space to be cleared and as a result of these chemical reactions the required uniform heating of the air would be obtained.

It should be noted that $\mathrm{Ca}(\mathrm{OH})_{2}$ also reacts with $\mathrm{CO}_{2}$ to yield $\mathrm{CaCO}_{3}$ and water. However, since reaction (3) is preferential, if sufficient time were allowed, $\mathrm{Ca}(\mathrm{OH})_{2}$ would be a final product only if the supply of atmospheric $\mathrm{CO}_{2}$ were inadequate. According to equation (3) each gram of $\mathrm{CaO}$ will combine with approximately 0.786 grams of $\mathrm{CO}_{2}$ and in so doing will liberate 775 calories. As explained above, only $520 \mathrm{cal} / \mathrm{m}^{3}$ are required for satisfactory evaporation of typical fog, so if it be assumed that all of the energy is to be supplied by reaction (3), only $0.67 \mathrm{I}$ grams of $\mathrm{CaO}$ and 0.528 grams of $\mathrm{CO}_{2}$ will be required per cubic meter of air. Since the normal $\mathrm{CO}_{2}$ content of the atmosphere is approximately $0.553 \mathrm{grams} / \mathrm{m}^{3}$ (0.03\% by volume), enough is available. Thus, under the ideal conditions assumed, to clear $2000 \mathrm{~m}^{3}$ of fog per second by this method would require about $\mathrm{I} .34 \mathrm{~kg}$ of $\mathrm{CaO}$ per second, costing about 4.2 cents per second.

In a practical case means would have to be provided for removing the reaction products from the atmosphere after the desired heating had been accomplished. The simplest method of accomplishing this would be to use particles of $\mathrm{CaO}$ which were large enough to fall rapidly to the ground. With such particles the indicated reactions would not be completed and some of the material would be wasted. It is impossible to state whether the smallest usable particles (about roo microns in diameter) would react at a sufficient rate to render the method feasible. There is also some question as to the form of the reaction products which might comprise aggregates of finely divided particles which would disintegrate before reaching the ground. Although the method has interesting possibilities, it cannot be stated definitely whether or not it is practicable owing to the lack of specific information on essential points. There is no apparent reason why the quicklime method should be appreciably more efficient than the calcium chloride method (to be discussed presently), in practical applications of which the amount of material

\footnotetext{
${ }^{8}$ Reaction heats obtained from data in (Bichowsky and Rossini, "Thermo-Chemistry of Chemical Substances" I936).
} 
actually required has been found to be more than nine times the theoretical minimum.

Blasts of air, heated by any convenient method, have also been suggested as a means of supplying the energy required for the evaporation of natural fog, but unless large quantities of air were handled it would probably be very difficult to obtain uniform heating. However, the method is undoubtedly workable and, if adequate volumes of air were dealt with, the distribution problem would be considerably simplified and other important practical advantages would be realized, as will be evident from the discussion in the fourth section.

As stated in the Prefatory Note, it has also been suggested that heat for the evaporation of fog particles could be supplied to them directly by means of radiant energy which could be distributed throughout a considerable volume from a relatively small source, quite independently of the wind. It is well known that both the liquid water contained in fog droplets and certain gaseous constituents of the atmosphere, notably water vapor and carbon dioxide, have numerous intense absorption bands in the infrared regions of the spectrum. Moreover, there are certain wavelengths at which absorption due to atmospheric gases is small compared to that caused by liquid water. If sufficient radiant energy could be provided at such wavelengths, the heat of vaporization might be supplied to the fog drops directly, and the air temperature would need be raised only enough to accommodate the additional water vapor from the evaporated droplets. The required speed of evaporation. would be secured by supplying radiant energy at a sufficient rate. If the method operated ideally, the total energy required for the dissipation of a typical fog (containing $0.2 \mathrm{gm}$ of liquid water per cubic meter at $20^{\circ} \mathrm{C}$ ) would be about $\mathrm{I} 75 \mathrm{cal} / \mathrm{m}^{3}$ which is roughly only one-third the energy needed when the heat is applied non-selectively.

Unfortunately this method cannot be used as there are available no sufficiently intense sources of appropriate bands of infrared radiations. If any of the usual hot body sources were employed, most of the radiant energy would be absorbed by atmospheric gases, assuming that none escaped as visible light. There is another serious difficulty arising from the exponential nature of the absorption process. The particles nearer the source would be forced to evaporate at a high rate, causing unnecessary warming of the surrounding air, while drops beyond a certain distance would not receive enough energy to complete their vaporization. These effects would tend to reduce greatly the efficiency of the process, and in practice it would probably have no worthwhile advantages over the direct heat application method. It should be noted that, of all the methods discussed in this paper, this is the only one inherently adapted to action at a distance.

\section{Evaporation by Removal of Water Vapor}

The remaining method of fog dissipation to be considered is the one whereby evaporation of the fog particles is induced by removing a portion of the atmospheric water vapor. Any practical method for doing this will involve a condensation process or a chemical reaction, either of which will be accompanied by the release of heat. Ordinarily, the heat liberated will be uniformly distributed and no unfavorable convective action will result. The liberation of heat is one of the important advantages of such methods since it initially accelerates the evaporation of the fog particles. The simultaneous removal of water vapor also hastens evaporation and, in addition, prevents recondensation if the cleared air subsequently cools-a possibility which exists with all of the straight heat application methods.

The condensation method of fog dissipation can be applied by using any of a number 
of materials which have the property of spontaneously condensing atmospheric water vapor upon themselves. Examples are micro-porous substances like silica gel and hygroscopic materials such as sulfuric acid, certain strong alkalies and certain salts. Owing to its extreme deliquescence, cheapness and relative innocuousness, the salt calcium chloride appears to be particularly suitable.

Several of these materials might be used in the form of small, initially dry particles which could be dropped through the fog to be cleared. Others, like calcium chloride, are so extremely hygroscopic that they could be utilized in the form of relatively large sprayed drops of a saturated aqueous solution. Any of the materials in finely divided form could be used in apparatus which, although retaining the drying agent, would distribute large quantities of cleared and dehumidified air which, like the heated air blasts previously mentioned, would evaporate the fog. With such an arrangement only a small portion of the air to be cleared need be passed through the apparatus. By drying this fraction sufficiently it could be mixed, by means of blowers, with a larger volume of fog and still effect the relative humidity reduction necessary for the complete and rapid evaporation of the fog particles. The evident flexibility of the condensation method is one of its chief advantages.

The quantity of drying material actually required depends upon its hygroscopicity and the method whereby it is utilized. As an example it will be assumed that calcium chloride is to be used to dissipate a typical fog $\left(\right.$ at $\left.20^{\circ} \mathrm{C}\right)$ by reducing the atmospheric relative humidity to $90 \%$. In order to determine the minimum quantity of calcium chloride theoretically required, it will be assumed that the particles used are exposed to the air long enough to become diluted to a $14 \%$ solution, at which concentration they would have an equilibrium relative humidity of $90 \%$. Thus if the calcium chloride is initially anhydrous, each gram will eventually condense upon itself 6.15 grams of atmospheric water vapor. In so doing it will liberate about 3720 calories, supplied by the heats of solution, dilution and condensation. If only 0.096 grams of calcium chloride are distributed throughout each cubic meter of air, 0.59 grams of atmospheric water vapor will be condensed and 356 calories will be released per cubic meter, and the relative humidity will thereby be reduced to $90 \%$. If the liquid water content of the fog is initially $0.2 \mathrm{gm} / \mathrm{m}^{3}$ after the droplets have completely evaporated the cleared and slightly warmed air will have a relative humidity of $91.7 \%$. If the air should be cooled down to the original temperature of $20^{\circ} \mathrm{C}$ by radiation and conduction, the relative humidity would rise only to $96.6 \%$ and recondensation could not occur. If $78 \%$ calcium chloride (the commercial grade) were used under the ideal conditions assumed, the clearing of $2000 \mathrm{~m}^{3}$ of fog per second would evidently require only $0.25 \mathrm{~kg}$ of material per second.

Unfortunately, in practice it is impossible to utilize either calcium chloride or any other hygroscopic substance with complete efficiency owing to the rapidity with which water vapor must be removed. The results of actual fog dissipation tests with calcium chloride indicate that when it is effectively used the clearing of $2000 \mathrm{~m}^{3} / \mathrm{sec}$ requires about $2.3 \mathrm{~kg}$ of $78 \%$ dry calcium chloride per second. Thus the quantity of material actually required is more than nine times the theoretical minimum.

\section{Conclusions}

The more important advantages and shortcomings of various possible methods of fog dissipation have been indicated. Most of the physical removal methods are relatively direct and rapid in their action and, in the main, require much less power to disperse fog 
at a given rate than the evaporation methods. However, they suffer from the disadvan tage that since the relative humidity of the cleared air is not reduced, both the extent and duration of the clearing are seriously limited by the filling-in effects of atmospheric turbulence. The apparatus required for the application of most methods of this type appears to be more or less impractical, chiefly because of its required size which is necessarily large owing to the fact that all of the air to be cleared must be acted upon directly. Of the physical removal methods discussed the only one which seems worthy of further consideration is that which utilizes charged, falling particles. Other investigators have tried and abandoned this method but perhaps the main difficulty was that the experiments were attempted on too grand or spectacular a scale as, for example, in cutting holes through clouds.

Although the evaporation methods of fog dissipation require about nine times as much power as some of the physical removal methods ${ }^{9}$ and are less direct and rapid in their action, they nevertheless appear to offer the best promise of success, principally because the limiting effects of atmospheric turbulence are greatly reduced by virtue of the lowered relative humidity of the cleared air. This is particularly true of methods involving the condensation and permanent removal of atmospheric water vapor. In some evaporation methods the required apparatus is of a reasonably practical nature and apparently can be arranged so that only a fraction of the fog to be cleared need be passed through it. This not only reduces the size, but it also increases the mobility of the necessary equipment. Such an arrangement is obviously not possible with any physical removal method.

If the details of its application could be satisfactorily worked out, the most economical process of evaporating fog, counting material costs alone, would evidently be that method in which all of the fog to be cleared is uniformly heated sufficiently to cause satisfactorily rapid vaporization of the fog particles. If the heating could be accomplished by appropriately burning fuel oil in the atmosphere, the cost of clearing 2000 $\mathrm{m}^{3} / \mathrm{sec}$ would apparently not exceed 0.2 cents $/ \mathrm{sec}$.

Evaporation methods which involve the actual removal of water vapor are, as a class, superior to those wherein the required relative humidity reduction is effected solely by the application of heat, principally because elimination of a sufficient amount of atmospheric water vapor prevents subsequent recondensation of the evaporated fog particlesa possibility which exists in all of the straight heat application methods. Of the materials which might be used in the condensation method, the hygroscopic salt calcium chloride appears to offer the best possibilities. It is quite effective, inexpensive and relatively harmless. Moreover it can be easily stored and easily distributed in effecting a clearing, and may be used either in the form of a dry powder or a saturated aqueous solution. The theoretical minimum amount of calcium chloride required costs fully 4.5 times as much as the corresponding quantity of fuel oil needed in the direct heat application method. Nevertheless, it is believed that the calcium chloride method is preferable.

The calcium chloride method of fog dissipation was selected for development at Round Hill several years ago. The basic processes of the general method were studied and two different practical applications have been extensively investigated. One of these involves the use of distributed calcium chloride spray. The other uses calcium chloride powder which is confined within a large drying unit from which is discharged cleared and

${ }^{9}$ Theoretically, to clear $2000 \mathrm{~m}^{3} / \mathrm{sec}$ by the Cottrell process would require about $500 \mathrm{kw}$; to clear the same quantity of foggy air by an evaporative process would require approximately $4400 \mathrm{kw}$. 
dehumidified air. The development of these methods and their application to the practical dissipation of natural fog are described in detail by the three sections which follow.

\section{REFERENCES}

I92 I Aero. Res. Comm. Reports and Memo., No. 727 (London).

Andrade, E. N. Da C.

1936 The Coagulation of Smoke by Supersonic Vibrations,

Transactions of the Faraday Society, Vol. 32, pp. I I I I-I I I 5.

BichowsKy AND RossinI

I936 Thermo-Chemistry of Chemical Substances.

BRANDT, O.

I936 Über das Verhalten von Schwebstoffen in schwingenden Gasen bei Schall- und

BRAnDt, O.

Ultraschallfrequenzen, Kolloid Zeits. Bd. 76, S. 272-278.

I937 Über die Frequenzabhängigkeit der Schallabsorption im Aerosol, Kolloid Zeits. Bd. 8I, S. 2-6.

Brandt, O., Freund, H., and Hiedemann, E.

I936 Zur Theorie der akustischen Koagulation, Kolloid Zeits. Bd. 77, S. Io3-1 I 5.

Brandt, O., Freund, H., and Hiedemann, E.

I937 Schwebstoffe im Schallfeld. Zeits. f. Physik, Bd. IO4, S. 5 I I-533.

Brandt, O., and Hiedemann, E.

I936 The Aggregation of Suspended Particles in Gases by Sonic and Supersonic Waves, Transactions of the Faraday Society, Vol. 32, pp. I IOI-I I Io.

Houghton H. G.

I932 The Size and Size Distribution of Fog Particles, Physics, Vol. 2, pp. 467-475. Houghton, H. G. and Radford, W. H.

I938 On the Measurement of Drop Size and Liquid Water Content in Fogs and Clouds, Papers in Physical Oceanography and Meteorology, Mass. Inst. of Tech. and Woods Hole Oceanographic Inst., Vol. VI, No. 4, November I $93^{8}$.

Humphreys, W. J.,

1926 Rain Making and Other Weather Vagaries.

LADENBURG, R.

I930 Untersuchungen über die physikalischen Vorgänge bei der sogenannter elektrischen Gasreinigung, Annalen der Physik, Bd. 4, S. 863-897.

Penney, G. W.

I937 A New Electrostatic Precipitator. Electrical Engineering, Vol. 56, pp I 59-163. 


\title{
II. A METHOD FOR THE LOCAL DISSIPATION OF NATURAL FOG BY MEANS OF SPRAYED CALCIUM CHLORIDE SOLUTION ${ }^{1}$
}

\author{
By H. G. HOUGHTON
}

\section{INTRODUCTION}

As a result of the survey of the possible methods of fog dissipation which has been presented in the preceding section it was concluded that the most promising possibility was the evaporation method in which the requisite relative humidity reduction is accomplished by the absorbing action of hygroscopic particles. It is the purpose of this paper to examine this method in detail and to determine, finally, how much hygroscopic material would be required to dissipate the fog in a given volume. Although the use of hygroscopic powders for the dissipation of fog has often been suggested, and in some instances actually tried, no complete examination of the problem on a scientific basis has previously been made.

In the application of the proposed method there are two fundamental conditions which must be satisfied. First, the hygroscopic particles must be so distributed through the volume which is to be cleared that the relative humidity will be reduced at every point by an amount sufficient to induce the prompt evaporation of the fog drops. Secondly, the hygroscopic particles must be removed from the atmosphere after they have absorbed their quota of water vapor. Otherwise a secondary fog of hygroscopic particles would be produced which might be as objectionable as the natural fog. Although there are other possibilities, one of which is discussed in the fourth section of this paper, the simplest method for accomplishing both the proper distribution and the removal of the particles is to release particles, which are large enough to fall fairly rapidly, above the volume which is to be cleared. Although it is desirable that the particles be small enough so that they will have condensed the maximum possible quantity of water vapor on reaching the ground, it is usually necessary to use somewhat larger particles to insure their removal by gravity within a reasonable time. The criteria for the selection of the optimum particle size are discussed more fully below.

In the case of fogs accompanied by little or no wind it is evidently necessary to provide a means for distributing the hygroscopic particles above the entire volume which it is desired to clear. The distribution problem is simpler when the fog is accompanied by an appreciable wind having a fairly constant direction. In this case the hygroscopic particles may be released at a suitable height along a line perpendicular to the wind direction. A curtain of falling hygroscopic particles is thereby produced through which the fog is carried by the wind. The clearing would then appear in the form of a lane or tunnel extending in a down-wind direction.

Calcium chloride was selected as the most suitable hygroscopic material because of its many advantages. It is extremely hygroscopic, relatively inexpensive and non-toxic. Although it would evidently be desirable to use a nearly anhydrous form of calcium chloride it was found that it was not immediately available in particles of the desired size. It appeared to be undesirable to undertake the development of methods for producing, storing and discharging a dry material of the required characteristics until the gen-

1 The general method of fog dissipation described herein is covered by Houghton patents U. S. No. 2,052,626 (I936) and British No. 449,321 (1934). 
eral method had been thoroughly investigated. It was therefore decided to use sprayed drops of a saturated aqueous solution of calcium chloride. Such a solution has an equilibrium vapor pressure of about one-third that of pure water.

The detailed investigation of the method of fog dissipation described in this section has been divided in to three parts. The first part involves the determination of the relative humidity required to cause the evaporation of the fog drops at the desired rate. The second part is concerned with the rate at which the hygroscopic particles (in this case drops of a saturated solution of calcium chloride) condense water vapor. The third part covers the selection of the proper size of the calcium chloride drops based on a compromise between the rate of condensation of water vapor and the desired velocity of fall, and also the development of a means for producing drops of approximately this size. Given all of this information it should be possible to compute the amount of calcium chloride solution required to dissipate a given volume of fog, and so to determine the practicability of the method.

\section{Drop Evaporation}

The evaporation of small water drops has been treated in an earlier paper (Houghton I933). The most significant result of this investigation is expressed by the equation

$$
\begin{aligned}
& \frac{d W}{d t}=2 \pi k a\left(D_{0}-D\right) \mathrm{g} / \mathrm{sec} \\
& \frac{d W}{d t}=\text { rate of change of drop weight. } \\
& k=\text { diffusion coefficient of water vapor in air. } \\
& a=\text { diameter of drop. } \\
& D_{0} \text { and } D=\text { respectively the water vapor densities at the surface of the } \\
& \text { drop and at a distance from the drop. }
\end{aligned}
$$

This expression states that the rate of evaporation of a drop is proportional to its diameter and not to the surface of the drop as of ten assumed. If $A$ is the initial drop diameter, the relation between the diameter of an evaporating water drop and the time is, from Eq. (I)

$$
a^{2}=A^{2}-8 k\left(D_{0}-D\right) t
$$

and the total time $T$ required for the complete evaporation of a drop of initial diameter $A$ is

$$
T=\frac{A^{2}}{8 k\left(D_{0}-D\right)}
$$

The experimental work reported in the paper on drop evaporation (Houghton I933) definitely showed that the rate of evaporation was proportional to the drop diameter in accordance with Eq. (I). It was difficult, however, to obtain good quantitative agreement because the drop temperature, and hence $D_{0}$, could not be accurately determined. Since the evaporative cooling may reduce the drop temperature as much as $15^{\circ} \mathrm{C}$ below the ambient temperature this factor is of considerable importance in the computation of the time of evaporation. Approximate values for the drop temperature may be obtained from the psychrometric equation (Houghton 1933) but Fuchs (1934) has shown that 
much more satisfactory results can be obtained by equating the loss of heat due to the evaporation to the gain by conduction, the effects of convection and radiation being negligible in most cases. The heat gained by conduction is

$$
H_{1}=2 \pi a K\left(T-T_{0}\right) \mathrm{cal} / \mathrm{sec} \text {. }
$$

where $\quad K=$ coefficient of heat conductivity for air.

$T_{0}$ and $T=$ respectively the temperature of the drop and of the air at a distance.

From Eq. (I) the heat used for the evaporation is

$$
H_{2}=2 \pi a k\left(D_{0}-D\right) L \mathrm{cal} / \mathrm{sec} \text {. }
$$

where

$$
L=\text { latent heat of evaporation of water. }
$$

Equating (4) and (5)

$$
T-T_{0}=\frac{k L}{K}\left(D_{0}-D\right) .
$$

Since it is difficult to obtain a suitable analy tic expression relating $D_{0}$ and $T_{0}$ it has been found best to solve Eq. (6) by "cut and try" methods with the aid of an appropriate table for $D_{0}$. Since both $k$ and $K$ are functions of the temperature, values should be selected for some average temperature lying between $T_{0}$ and $T$. The geometric mean of $T_{0}$ and $T$ seems to be an appropriate value.

By this method Fuchs (1934) obtained an excellent agreement with some of the author's experimental data for a water drop evaporating in dry air. In the case of the data for air containing some water vapor the agreement was not so good but a reëxamination of the experimental method has now indicated that this was due largely to inaccurate determinations of the water vapor pressure, as suggested by Fuchs. Table I shows the agreement between some of the experimental and computed values of the $8 K\left(D_{0}-D\right)$ term in Eqs. (I), (2), and (3) based on more accurate values of the ambient relative humidity during the experiments. For the purposes of this paper the time required for the evaporation of fog drops has been computed as a function of drop diameter and ambient relative humidity for air temperatures of $10^{\circ}$ and $20^{\circ} \mathrm{C}$. These

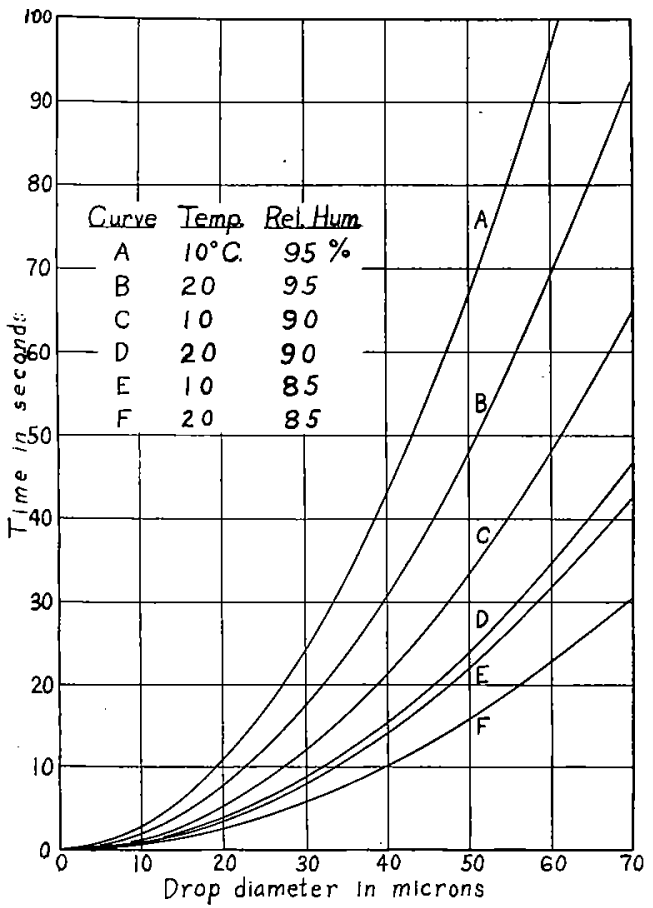

FIG. I.-The time required for the complete evaporation of small water drops for several ambient conditions. data are plotted as a family of curves in Fig. I.

The computations and experimental results described above assume that the drop is stationary with respect to the air. This is practically true for small fog drops but some of the larger ones have an appreciable velocity of fall, and relative motion with respect to 
the air may considerably increase the rate of diffusion as will be shown in detail in connection with the condensation of water vapor on drops of calcium chloride solution. This effect is not so marked in the case of an evaporating drop since the velocity of fall decreases as the drop evaporates. As an example of this effect, it has been computed that at

TABLE I

\begin{tabular}{ccccc}
\hline \hline $\begin{array}{c}\text { AMmient } \\
\text { TEMP. }\end{array}$ & $\begin{array}{c}\text { AMbient } \\
\text { REL. HUM. }\end{array}$ & $\begin{array}{c}\text { Computed } \\
\text { DROP TEMP. }\end{array}$ & $\begin{array}{c}\text { Computed } \\
8 k\left(D_{0}-D\right)\end{array}$ & $\begin{array}{c}\text { Experimental } \\
8 k\left(D_{0}-D\right)\end{array}$ \\
\hline $9.0^{\circ} \mathrm{C}$ & $0 \%$ & $-1.2^{\circ} \mathrm{C}$ & $8.02 \times 10^{-6}$ & $8.08 \times 10^{-6}$ \\
14.7 & 0 & +1.87 & 10.30 & 10.67 \\
21.7 & 0 & 5.3 & 13.31 & 13.32 \\
22.0 & 0 & 5.45 & 13.45 & 13.42 \\
20.0 & 35 & 10.9 & 7.56 & 7.32 \\
20.3 & 55 & 14.25 & 5.06 & 4.90 \\
20.3 & 79 & 17.6 & 2.23 & 2.04 \\
19.8 & 80 & I7.3 & $2.1 \mathrm{I}$ & 2.09 \\
\hline
\end{tabular}

a temperature of $20^{\circ} \mathrm{C}$ and a relative humidity of 90 per cent, a 100 micron drop, allowed to fall freely, would completely evaporate in about 70 seconds as against 96 seconds were the drop stationary with respect to the air. Under the same conditions the comparable figures for a 50 micron drop are 21.4 seconds and 24.0 seconds respectively.

Fog particles are not pure water drops but contain a small amount of dissolved matter which, in the case of sea fogs, has been found to consist principally of the salts contained in sea water. Measurements have shown that an average of $70 \mathrm{mg}$ of salt is contained in each liter of fog water. This has no appreciable effect on the evaporation of the drop until its volume is reduced to about one two-hundredth of its initial value. Since the "visibility" is inversely proportional to the square of the drop diameter for a constant number of drops (Stratton and Houghton I93I), a reduction in volume of this amount would increase the visibility 34 times, the equivalent of practically clear air. It is therefore apparent that for the purposes of fog dissipation computations the particles of sea fog may be considered to evaporate in the same manner as drops of pure water. This conclusion may not be valid for fogs occurring near large cities since there is reason to believe that such fogs may contain much larger quantities of dissolved material.

\section{The Condensation of Water Vapor on Drops of Calcium Chloride Solution}

The condensation of water vapor on drops of calcium chloride solution presents fundamentally the same diffusion problem as that of the evaporation of water drops, which has been treated above. There are, however, two important modifications which must be applied to Eqs. (I) and (2). As water vapor condenses on a drop of calcium chloride solution the drop becomes a more dilute solution thus changing the vapor pressure at the surface of the drop. That is, $D_{0}$ in Eqs. (I) and (2) becomes a function of the concentration of the calcium chloride solution and for a given initial concentration $D_{0}$ is a function of the ratio $(a / A)^{3}$. The second point of difference arises from the fact that the drops of calcium chloride solution which are to be used for fog dissipation must have a considerable velocity of free fall as pointed out at the beginning of the paper. This relative motion between the drop and the atmosphere is great enough to seriously affect the apparent rate of diffusion, as will be seen below.

In view of the difficulty of taking these factors in to account theoretically, particularly 
the effect of a relative velocity between the drop and the atmosphere, it was decided to examine the problem experimentally. The special apparatus which was constructed for this purpose is shown diagrammatically in Fig. 2. The drop was suspended on a fine paraffined glass filament which did not appreciably alter the spherical form of the drop and which also served to insulate the drop thermally so that it would be free to assume its true equilibrium temperature. The drop was observed through a microscope fitted with an ocular micrometer and the amount of water vapor condensed on the drop was measured by noting the increase in drop diameter. The effect of a relative motion between the drop and the - atmosphere was investigated by equipping the apparatus with a fan and a calibrated vane anemometer so that any desired air velocity could be obtained. The air within the instrument was maintained substantially saturated with water vapor by virtue of its constant circulation over the water reservoir. A wet

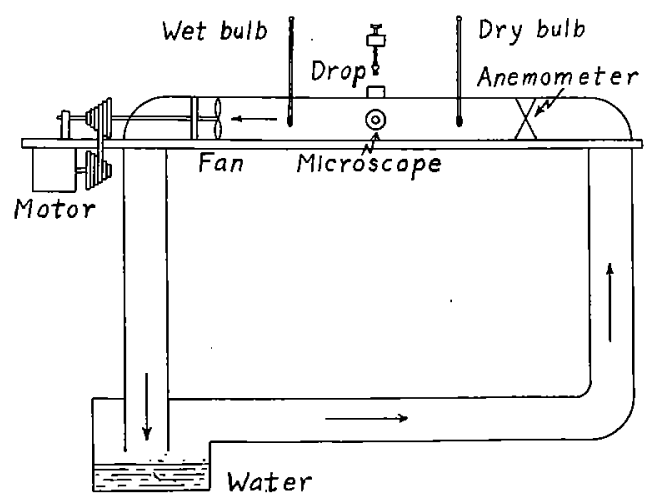

FIG. 2. - The apparatus used to determine the rate of condensation of water vapor on drops of calcium chloride solution in a saturated atmosphere as a function of drop size, temperature and the velocity of the atmosphere with respect to the drop. and a dry bulb thermometer were used to measure the actual water vapor pressure within the apparatus. The experiments were performed by introducing a drop of calcium chloride solution which was saturated at the

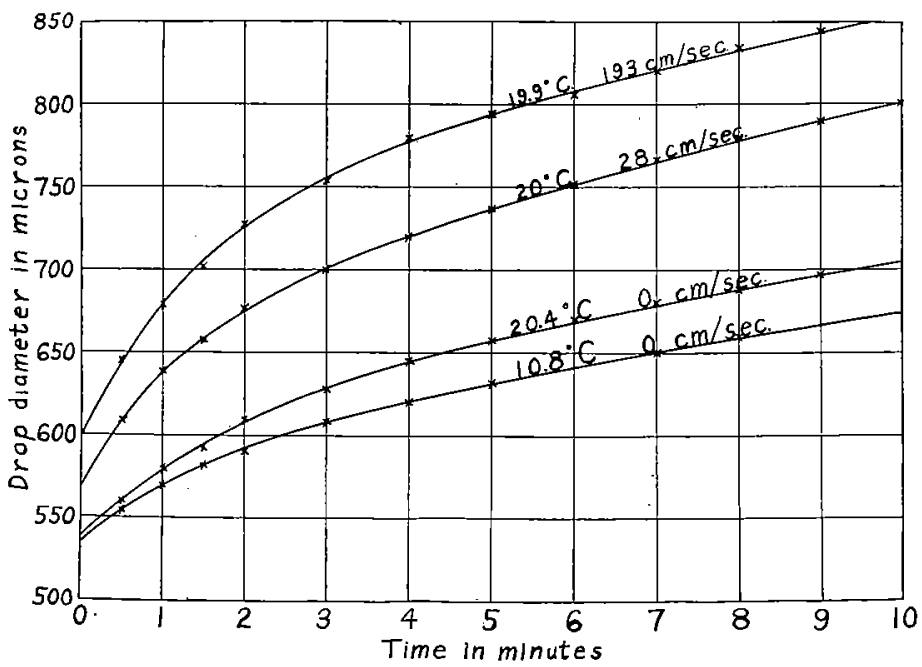

FIG. 3.- Typical curves illustrating the type of data obtained with the apparatus shown in Fig. 2. The atmosphere is practically saturated with water vapor. The velocity figures give the relative velocity between the drop and the atmosphere. The drops are initially a saturated solution of calcium chloride at the ambient temperature.

ambient temperature and measuring the drop diameter as a function of time. The initial drop size, the ambient temperature and the air velocity past the drop were varied. Some typical experimental curves illustrating the results are reproduced in Fig. 3 . 
For the case of zero relative velocity between the drop and the surrounding atmosphere Eq. (2) should apply with the aforementioned restriction that $D_{0}$ is a variable which is a function of the calcium chloride concentration or, more conveniently, of some power of the ratio $a / A$. In order to verify this application the experimental data for zero air velocity past the drop were plotted using abscissae with a linear time scale and ordinates with a scale proportional to $a^{2}$. Differentiating Eq. (2)

$$
\frac{d\left(a^{2}\right)}{d t}=8 k\left(D-D_{0}\right)
$$

Hence the slope of the experimental curves at any point gives the value of the term $8 k\left(D-D_{0}\right)$ as a function of the calcium chloride concentration which corresponds to the

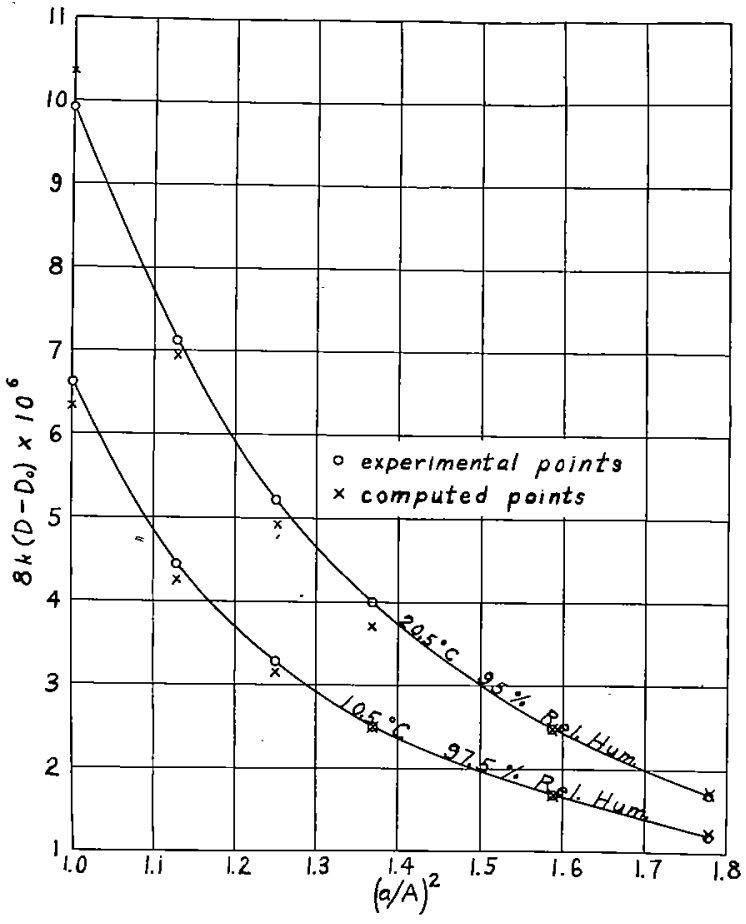

FIG. 4--The average experimental values of the term $8 k\left(D-D_{0}\right)$ in the diffusion equation for the case of zero relative velocity between the drop and the atmosphere. 'The crosses represent computed values. selected value of $a$. As indicated by the theory it was found that this slope was independent of the initial drop diameter $A$ and was a function only of the ambient temperature of the calcium chloride concentration which can be expressed as $(a / A)^{2}$. The average experimental values of $8 k\left(D-D_{0}\right)$ are plotted against $(a / A)^{2}$ for two ambient temperatures in Fig. 4 . In each case the drop was initially a saturated solution of calcium chloride at the particular ambient temperature.

For the sake of comparison the values of $8 k\left(D-D_{0}\right)$ were then computed as a function of $(a / A)^{2}$ in a manner similar to that employed in the case of drop evaporation. Strictly, the heat of dilution of the calcium chloride solution should be added to the heat of condensation in computing the drop temperature, but since it represents a very small addition which is largely counterbalanced by the small heat losses due to radiation and convection Eq. (6) was used unchanged. The values of $D_{0}$ were then obtained from available data on the vapor pressure of aqueous calcium chloride solutions as a function of concentration and temperature. The values of $8 k\left(D-D_{0}\right)$ computed in this manner for the experimental ambient conditions are also plotted in Fig. 4 and it will be seen that the agreement with the experimental values is quite good.

To determine the effect of a relative velocity between the drop and the surrounding atmosphere on the rate of condensation, the apparent values of the $8 k\left(D-D_{0}\right)$ term were obtained from the experimental data as a function of the relative velocity and of the ratio $(a / A)^{2}$ in a manner entirely similar to that described above for the case of zero relative velocity. It was found that the effect of the relative velocity could be expressed 
by a coefficient $C$, which is a function only of the relative velocity, to be applied to the value of $8 k\left(D-D_{0}\right)$ for zero relative velocity. Thus

$$
a^{2}=A^{2}+8 k C\left(D-D_{0}\right) t
$$

The experimental values of $C$ are given in Fig. 5. Namekawa and Takahashi (I937) have published a similar curve for the effect of velocity on the evaporation of water drops. The values of their coefficient are somewhat greater than those given in Fig. 5.

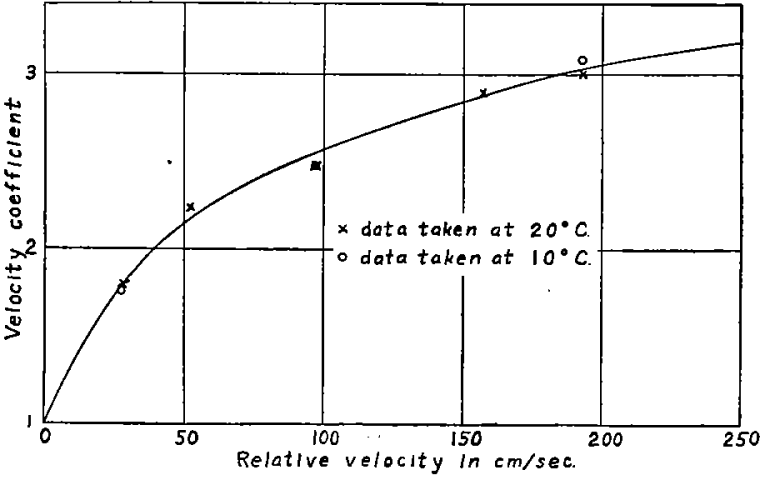

FIG. 5.-Experimental values of the coefficient $C$ which introduces the effect of a relative velocity between the drop and the atmosphere in the diffusion equation.

More recently Frössling (1938) has presented the results of a series of careful determinations of the velocity coefficient for evaporating drops of water and of other substances. He finds that the velocity coefficient may be expressed in the form $\mathrm{I}+k \sqrt{R e}$ where $R e$ is the Reynolds' number and $k$ is a constant which is dependent only on the material of the drop. For water the value of this constant is 0.229 . The values of $C$ as computed from Frössling's formula do not agree very well with those presented in Fig. 5. It has also been found the values of $C$ determined from the results of the fog dissipation tests described in the third section of this paper fit the curve of Fig. 5 very well. It has therefore been considered preferable to use this curve rather than Frössling's values.

Before the desired rate of condensation on falling drops can be obtained from the data presented above it is necessary to know the terminal velocity of fall of the drops so that the proper values of $C$ may be selected. The velocity of fall also determines the time during which the drop will remain in the atmosphere. Stokes' law is not applicable because of the relatively high velocities of fall but experimental values of the resistance coefficients of spheres are available (Handbuch der Experimentalphysik) from which the terminal velocities of freely falling drops may be computed. The results of such computations for drops of a saturated solution of calcium chloride are plotted in Fig. 6.

For fog dissipation purposes it is necessary that a large number of drops fall through the fog simultaneously. Therefore there was some question as to the application of the 
data of Fig. 6 which assume an isolated drop. It was decided to perform a simple experiment to determine the actual velocity of fall of a large number of drops falling simultaneously. An elevated header pipe carrying a number of spray nozzles was used as a source of the drops. The experiment was performed on a day during which there was a steady wind having a direction normal to that of the spray nozzle header pipe. A number of grease-coated microscope slides such as are utilized in the measurement of fog particle size (Houghton I932) (Houghton and Radford I938) were arranged in special slide holders at suitable distances down-wind from the spray nozzles. After the spray curtain had reached its equilibrium condition the slides were exposed simultaneously for a short period by means of electrically operated shutters on the slide holders. The wind velocity was measured at three elevations between the spray nozzles and the ground during the test. The size of the drops collected by each slide was determined by means of the fog microscope (Houghton 1932) (Houghton and Radford 1938) and it was found that each slide had collected a range of drop sizes owing to the turbulent vertical component of the wind. Since the vertical motions tend to average out over a reasonable period of time, the average or predominant drop size was taken as the size which would have reached the slide in the absence of vertical wind components.

From the drop size data, the wind velocity, the height of the spray nozzles and the horizontal distances from the spray nozzles to the slides in the direction of the wind it was then possible to determine the average velocities of fall of the drops. The elevation of the nozzles was such that the average velocity of fall approximated the terminal velocity of the drops within the accuracy of the experiment. The experimental values have been spotted on Fig. 6. Since they do not lie far from the computed curve it may be concluded that the number of drops used for fog dissipation is not sufficient to greatly modify their free fall velocities. Since they are based on more accurate observations the computed values have been used in the computations which follow.

It is now possible to determine the time required for a freely falling drop of calcium chloride solution to attain any given size by condensation in a saturated atmosphere. Dividing Eq. (7) by $A^{2}$, introducing the velocity coefficient $C$ and integrating

$$
T=A^{2} / C \int_{1}^{\left(a_{1} / A\right)^{2}} \frac{d(a / A)^{2}}{8 k\left(D-D_{0}\right)} .
$$

This expression gives the time $T$ required for a drop of a saturated solution of calcium chloride of diameter $A$ to attain a diameter $a_{1}$ when falling through an atmosphere of vapor density $D$. The integral may be evaluated graphically by replotting the data of Fig. 4 with I $/ 8 k\left(D-D_{0}\right)$ as a function of $(a / A)^{2}$. The results of such integrations for several ambient conditions are given in Fig. 7. The value of $C$ for a given drop diameter may be determined from Figs. 5 and 6 . Although $C$ varies continuously owing to the grow th of the drop the change is relatively small because of the short time of fall and the fact that the density of the drop decreases with dilution. Consequently only a small error will be introduced by the assumption of a constant value of $C$ for a given drop.

From Eq. (9) the diameter of the drop may now be determined as a function of time. For purposes of the subsequent computations it is more convenient to have these data in the form of "total water vapor condensed per drop" as a function of the "distance of fall." This may be done readily by introducing the velocity of fall thus leading to curves of the type presented in Fig. 8. 


\section{Production of Sprayed Drops of Suitable Size}

The most suitable drop size depends to some extent on the particular arrangement of the fog dissipation apparatus and on the conditions prevailing during fogs at the particular location. In general, however, it may be said that the drops should be as small as is consistent with their removal by gravity before they have been carried by the wind a distance exceeding Io to $20 \%$ of the expected length of the clearing. On this basis, for typical conditions the optimum drop diameter lies between $\mathrm{I} 00$ and 200 microns.

The simplest and generally the most satisfactory method of producing large numbers of drops of approximately the desired size is to spray the solution through suitable nozzles at a pressure of from 5 o to Ioolbs/in'. (Atomizing nozzles which use both air and solution under pressure produce drops which are much too small.) The first step in the search for a suitable spray nozzle was to determine the size of the drops produced by typical commercial spray nozzles. The drop sizes were determined microscopically by the method used for measuring the sizes of fog drops (Houghton I932) (Hough ton and Radford I938). It was found that the best of the commerical nozzles produced too wide a range of drop

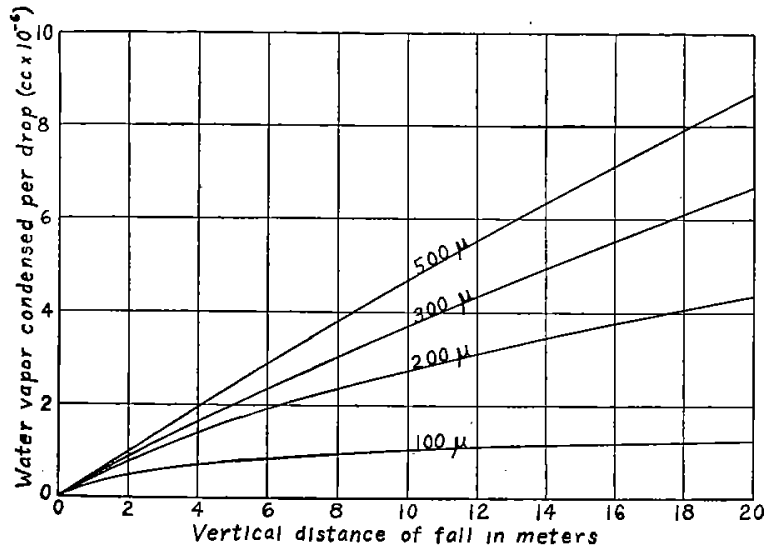

Fig. 8.--The total volume of water vapor condensed by a freely falling drop of calcium chloride solution as a function of the vertical distance fallen. These curves are derived from the central curve of Fig. 7 and therefore apply to a temperature of $20.5^{\circ} \mathrm{C}$ and a relative humidity of $95 \%$.

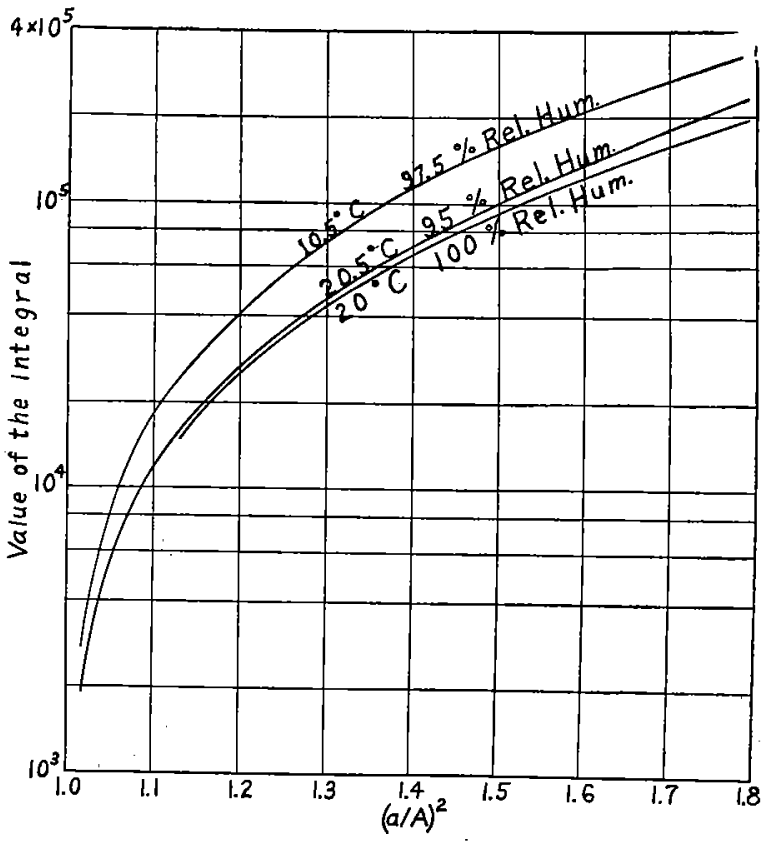

FIG. 7.-Values of $\int d(a / A)^{2} / 8 k\left(D-D_{0}\right)$ which determine the rate of condensation of water vapor on drops of calcium chloride solution. The two upper curves were obtained from experimental data while the lower curve was determined from computed results. sizes, most of the solution being delivered in the form of large drops which would be inefficient for fog dissipation purposes. A somewhat better spray nozzle which was a modification of a commercial type was finally developed by a "trial and error" method. This nozzle was sufficiently good to permit the first full-scale trials of the method of fog dissipation to be made, but it produced too many very large drops and also, in common with all known spray nozzles, a number of very small drops which would remain in suspension in the cleared space.

Because of the unsatisfactory status of the nozzle problem a more thorough investigation was undertaken as soon 
as the fog dissipation method had been successfully tested with the modified commercial type of nozzle mentioned above. This work consisted first of a comprehensive study of the factors affecting the formation of drops by spray nozzles which finally permitted formulation of the conditions for the production of drops within a minimum size range. The remaining part of the investigation was concerned with the development of a nozzle which would most nearly meet these conditions. A detailed discussion of this work on spray nozzles is beyond the scope of the present paper and it will be presented separately at a later date. For the purposes of this paper it will be sufficient to consider the drop size distribution data of the two types of nozzles which have been utilized for fog dissipation. These data are contained in Table II. The advantage of the improved nozzle lies in the smaller number of large drops formed and the consequent increase in the number of drops in the desired size range. The improved nozzle forms more very small drops (50 micron group) than the original nozzle but this difference is equalized because less than one-half as much solution need be sprayed through the improved nozzles to cause the same fog dissipating action. Also the above data do not include the effect of the special filters which are attached to the improved nozzles and which remove a large proportion of the small drops immediately after they are formed.

Before proceeding to the computations of the amount of calcium chloride solution required for the dissipation of fog under typical conditions there are several important

TABLE II

Drop Size Distribution Data for the Spray Nozzles Used

\begin{tabular}{|c|c|c|}
\hline \multirow{2}{*}{$\begin{array}{l}\text { Nominal diameter of drop group } \\
\text { (microns) }\end{array}$} & \multicolumn{2}{|c|}{$\begin{array}{l}\text { Number of drops in each size group formed when a total of } \mathrm{I} \text { cc of solution } \\
\text { is sprayed. }\end{array}$} \\
\hline & Original nozzle & Improved nozzle \\
\hline 50 & $43, \infty 0$ & 107,000 \\
\hline 100 & 22,200 & 84,000 \\
\hline 150 & 16,800 & 43,500 \\
\hline 200 & 10,300 & 28,600 \\
\hline 250 & 6,500 & 18,900 \\
\hline 300 & 4,500 & 9,900 \\
\hline 350 & 2,300 & 4,250 \\
\hline 400 & $2, \infty 00$ & 2,700 \\
\hline $45^{\circ}$ & 1,900 & 1,400 \\
\hline 500 & 1,600 & 1,100 \\
\hline 550 & 900 & 550 \\
\hline 600 & 800 & 370 \\
\hline 650 & 600 & 180 \\
\hline 700 & 400 & 90 \\
\hline 800 & 300 & - \\
\hline 900 & I 50 & - \\
\hline
\end{tabular}

points which must be considered. The rate at which water vapor is condensed by a drop of calcium chloride solution decreases steadily as the drop falls. Therefore, if sufficient solution is sprayed to remove the required amount of water vapor from the stratum immediately above the ground more water vapor will be condensed in the higher levels than is necessary. However, it has been found that in the case of a moderate wind $(5 \mathrm{~m} / \mathrm{sec}$ or more) the atmospheric turbulence is sufficient to largely equalize this non-uniform water vapor distribution if the elevation of the nozzles does not exceed Io to 20 meters. It has therefore been assumed that the total amount of water vapor condensed is removed uniformly with respect to height. 
Due to the irregular vertical components of the wind velocity, drops of equal size do not all reach the ground from a given height in the same time. Over a time interval corresponding to the duration of a fog dissipation test ( 5 to ro minutes) these vertical components tend to average out so that it is permissible to neglect this effect and assume that the time of fall of a drop is determined by its terminal velocity of fall in still air.

When there is a wind, drops of unlike size follow different paths in their fall to the ground, the large drops falling at a much steeper angle than the small ones. It follows that only the largest drops fall in saturated air, the smaller ones passing through air from which a portion of the water vapor has already been removed. An approximate correction for this effect can be made in the computations by assuming a relative humidity which is an average between the initial saturated value and the final relative humidity of the cleared air. It so happened that, because of the difficulty of maintaining saturated air in the experimental apparatus shown in Fig. 2, the data on the rate of condensation of water vapor were taken at relative humidities of from 95 to $97 \%$ so that these data are particularly well suited for the computations which are to be made.

The condensation of water vapor on the drops of calcium chloride solution releases a considerable amount of latent heat. Although a small portion of this heat is retained by the drops most of it is imparted to the air. The resultant temperature rise acts to reduce the relative humidity and so to increase the rate of evaporation of the fog drops. As will be seen below this heating effect is responsible for more than half of the total reduction in relative humidity and it must therefore be taken into account in the computation of the total quantity of calcium chloride solution required for the dissipation of a given volume of fog.

Due to the evaporation of the fog drops the relative humidity increases steadily during the evaporation process. However, to insure the rapid evaporation of the droplets, the quantity of water vapor removed must be large compared to the water contained in the fog drops so that this relative humidity increase is small and may usually be neglected in the computations.

The total amount of water vapor condensed by I cc of sprayed calcium chloride solution has been computed for two ambient temperatures and two heights of fall from the spray nozzle data given in Table II and curves of the type presented in Fig. 8. The results are presented in Table III. The computations were based on experimental data for the rate of condensation of water vapor on calcium chloride drops which were taken at relative humidities of from 95 to $97 \%$. The superiority of the improved spray nozzle is clearly brought out by the figures in the last two columns of the table.

Sufficient information is now available to permit computations to be made of the quantity of calcium chloride solution required to dissipate a given volume of fog. It will be assumed that it is desired to maintain a cleared space initially Io meters high and 40 meters wide ${ }^{2}$ in a fog accompanied by a wind velocity of $5 \mathrm{~m} / \mathrm{sec}$. This requires the handling of 2000 cubic meters of fog per second and is therefore equivalent to the assumptions made throughout this paper. It will be further assumed that the apparatus consists simply of a header pipe 40 meters long carrying a suitable number of spray nozzles, suspended Io meters above the ground in a direction normal to the wind velocity.

It is first necessary to determine the relative humidity required to evaporate the fog drops within the specified time. The time which can be allowed for the evaporation de-

\footnotetext{
2 The length of the clearing in the direction of the wind is determined by atmospheric turbulence as will be shown in
} the next section. It would probably be from 500 to 800 meters for the case assumed here. 
pends on the wind velocity and the size of the clearing produced. In this case a reasonable time is 20 seconds which corresponds to a distance of I00 meters since the wind velocity is $5 \mathrm{~m} / \mathrm{sec}$. It is not necessary that the few very large fog drops be completely evaporated within this time since they do not greatly affect the visibility. If, for example, all of the drops smaller than 50 microns diameter are completely evaporated the clearing will be satisfactory. Entering Fig. I at a point corresponding to 50 microns and 20 seconds it is found that a relative humidity of about $87.5 \%$ is required at $20^{\circ} \mathrm{C}$ and about $84 \%$ at $10^{\circ}$. It is apparent that the relative humidity varies rapidly for small changes in the assumed drop size and time of evaporation. For this reason a value of $90 \%$ was selected for the discussion in the preceding section since it is a convenient value which corresponds to the complete evaporation of most of the fog drops within a reasonable time.

TABLE III

\begin{tabular}{|c|c|c|c|}
\hline \multirow{2}{*}{ Height of FaLL } & \multirow{2}{*}{$\begin{array}{c}\text { AMBIENT } \\
\text { TEMPERATURE }\end{array}$} & \multicolumn{2}{|c|}{ Water Vapor Condensed per cc of Spray } \\
\hline & & Original nozzle & Improved nozzle \\
\hline $\begin{array}{l}\text { Io meters } \\
20\end{array}$ & $\begin{array}{l}\text { IO. } 5^{\circ} \mathrm{C} \\
20.5 \\
10.5 \\
20.5\end{array}$ & $\begin{array}{l}0.126 \mathrm{cc} \\
0.187 \\
0.213 \\
0.282\end{array}$ & $\begin{array}{l}0.303 \mathrm{cc} \\
0.405 \\
0.480 \\
0.616\end{array}$ \\
\hline
\end{tabular}

The relative humidity reduction is produced in part by the actual removal of water vapor and in part by the temperature rise due to the release of the latent heat of condensation of the water vapor. From the size, calcium chloride concentration and temperature of the sprayed drops at the ground level, it is readily possible to compute how much of the total heat of condensation is retained by the drops. Although this is a function of the height of fall, the size distribution of the sprayed drops and the ambient temperature it is found that it seldom amounts to more than $5 \%$ of the total heat evolved. It may be assumed, therefore, that about $95 \%$ of the latent heat of condensation or approximately $556 \mathrm{cal}$ is absorbed by the air for each gram of water vapor condensed. The temperature $T$ of the air after the condensation of the water vapor is given by the following expression

$$
T=T_{0}+\frac{556 w}{c_{p} M}
$$

where

$$
\begin{aligned}
T_{0} & =\text { ambient temperature. } \\
w & =\text { water vapor condensed in } \mathrm{g} / \mathrm{m}^{3} . \\
c_{p} & =\text { specific heat of air at constant pressure. } \\
M & =\text { mass of air in } \mathrm{g} / \mathrm{m}^{3} .
\end{aligned}
$$

The relative humidity of the air after the condensation process is

$$
\text { R.H. }=\frac{W_{0}-w}{W_{T}}
$$

whıre $\quad W_{0}$ and $W_{T}=$ the saturation water vapor densities at the temperatures $T_{0}$ and $T$ respectively in $\mathrm{g} / \mathrm{m}^{3}$. 
From these equations and a suitable table relating $W_{T}$ and $T, w$ may be determined as a function of the final relative humidity. For an ambient temperature of $20.5^{\circ} \mathrm{C}$ and a final relative humidity of $87.5 \%$ it is found that $w=0.78 \mathrm{~g} / \mathrm{m}^{3}$. Similarly at $10.5^{\circ} \mathrm{C}$ and $84 \%$ relative humidity $w=0.77 \mathrm{~g} / \mathrm{m}^{3}$. In each case the final air temperature is about $\mathrm{I} .5^{\circ}$ greater than the ambient temperature.

From the values given in Table III for a height of Io meters the quantities of calcium chloride solution ${ }^{3}$ required to condense the indicated amounts of water vapor can now be determined. For the original type of spray nozzle $6.1 \mathrm{I} \mathrm{cc} / \mathrm{m}^{3}$ are required at $10.5^{\circ} \mathrm{C}$ and $4.17 \mathrm{cc} / \mathrm{m}^{3}$ at $20.5^{\circ}$. For the improved type of nozzle only $2.54 \mathrm{cc} / \mathrm{m}^{3}$ are required at $10.5^{\circ} \mathrm{C}$ and $\mathrm{I} .92 \mathrm{cc} / \mathrm{m}^{3}$ at $20.5^{\circ}$.

In the typical case assumed above, 2000 cubic meters of fog must be cleared each second so that the total quantities of solution required are $\mathrm{I} 2.2 \mathrm{~L} / \mathrm{sec}$ and $8.3 \mathrm{~L} / \mathrm{sec}$ for the original nozzles at $10.5^{\circ} \mathrm{C}$ and $20.5^{\circ} \mathrm{C}$ respectively. For the improved nozzles the corresponding values are $5.1 \mathrm{~L} / \mathrm{sec}$ and $3.8 \mathrm{~L} / \mathrm{sec}$ respectively at $10.5^{\circ} \mathrm{C}$ and $20.5^{\circ} \mathrm{C}$.

The size of the cleared space which would result under the conditions assumed above is probably as small as could be expected to be of practical value. The quantities of calcium chloride solution required are fairly large but are still entirely within reason. It was therefore concluded that the method was practicable and merited a full-scale trial. The following section describes the design, construction and successful operation of an installation of practical size.

\section{REFERENCES}

Frössling, N.

I938 Über die Verdunstung fallender Tropfen, Gerlands Beitr. z. Geophys., Bd. 52, Fuchs, N. $\mathrm{I}-2$, S. $170-216$.

I934 Über die Verdampfungsgeschwindigkeit kleiner Tröpfchen in einer Gasatmosphäre, Physikalische Zeits. der Sowjetunion, Bd. 6, S. 224-243.

I932 Handbuch der Experimentalphysik, Bd. 4, Teil 2, S. 348.

Houghton, H. G.

I932 The Size and Size Distribution of Fog Particles, Physics, Vol. 2, pp 467-475.

I933 A Study of the Evaporation of Small Water Drops, Physics, Vol. 4, pp 419424 .

Houghton, H. G. and Radford, W. H.

I938 On the Measurement of Drop Size and Liquid Water Content in Fogs and Clouds, Papers in Physical Oceanography and Meteorology, Massachusetts Institute of Technology and Woods Hole Oceanographic Institution, Vol. VI, No. 4, November 1938.

Namekawa, T., and Takahashi, T.

I937 Evaporation of Water Drops, Kyoto Coll. Sci., Mem., Vol. 20, pp I39-I46.

Stratton, J. A., and Houghton, H. G.

I93I A Theoretical Investigation of the Transmission of Light Through Fog, Physical Review, Vol. 38, pp I 59-165.

${ }^{3}$ The solution is assumed to be saturated at the ambient temperature. At $20.5^{\circ} \mathrm{C}$ a saturated aqueous solution contains $42.8 \%$ by weight anhydrous calcium chloride and has a specific gravity of $\mathrm{I} .429$. At $10.5^{\circ} \mathrm{C}$ the respective values are $39.6 \%$ and 1.395 . 


\title{
III. THE DESIGN AND OPERATION OF A FOG DISSIPATOR UTILIZING SPRAYED CALCIUM CHLORIDE SOLUTION
}

\author{
By H. G. HOUGHTON AND W. H. RADFORD
}

The preceding section describes the results and conclusions of an investigation of the practicability of the local dissipation of natural fog by means of a spray of a saturated solution of calcium chloride. The results indicated that a cleared space of useful size could be maintained under typical natural fog conditions by the proper utilization of an entirely reasonable quantity of calcium chloride solution.

It is the purpose of this section to describe the design and operation of a full-scale experimental calcium-chloride-spray fog dissipator which was constructed at Round Hill in the spring of 1934. Although the clearing produced by this apparatus is so large that it could be considered to be of practical value under favorable conditions, the installation was designed and arranged only to permit a full-scale trial of the method under actual fog conditions and to make possible certain observations by means of which the computations and laboratory experiments described in the preceding section could be verified.

Basically, the general method of fog dissipation to be discussed consists in releasing drops of a saturated solution of calcium chloride at an elevation corresponding to the initial height of the desired clearing. These drops are so large that the force of gravity causes them to settle rapidly through the fog. As they descend they condense upon themselves, by virtue of their hygroscopic nature, a certain amount of atmospheric water vapor. The resultant reduction in relative humidity induces the evaporation of the fog droplets at a rate that is dependent upon their size and the amount of water vapor condensed.

It is evident that in this particular method the calcium chloride spray must pass through all of the air to be cleared, which means that in the case of a calm the spray must be distributed above the entire volume wherein the clearing is desired. When the fog is accompanied by a steady wind, on the other hand, the spray can be released at a suitable elevation along a line perpendicular to the wind direction. All of the fog passing through the curtain of sprayed drops so formed suffers a reduction in relative humidity, and consequently a clearing appears on the down-wind side of the apparatus. The wind greatly increases the amount of fog which must be treated to maintain a suitable clearing, but at the same time it tremendously simplifies the problem of distributing the spray.

\section{Considerations Which Determined the Size of the Experimental Apparatus}

At Round Hill fogs are normally accompanied by southerly winds having velocities of from 3 to $7 \mathrm{~m} / \mathrm{sec}$. It was decided therefore to use the second type of spray distribution mentioned above and to dispense the spray by means of a number of nozzles attached to an elevated horizontal pipe line extending in the East-West direction. The determination of the proper height and length of this pipe line were two of the first considerations.

It was desired to make the dimensions of the experimental apparatus as small as would be consistent with the effective utilization of the sprayed solution and with the 
formation of a cleared space large enough to be readily observed. The mixing effects of atmospheric turbulence were the principal factors governing the selection of a suitable height and length for the elevated pipe line. Although the quantity of water vapor condensed by the calcium chloride spray approaches a maximum as the distance of fall increases, it is also true that since the solution has its maximum concentration at the point of release more water vapor is removed there than at lower levels. For heights up to Io or 20 meters the normal atmospheric turbulence with wind velocities of from 3 to 7 meters per second causes enough mixing to largely overcome this non-uniform removal of water vapor. For greater heights of fall (or in still air) more solution would have to be sprayed to insure the removal of a sufficient amount of water vapor from the lowest air stratum. Another consideration in the choice of an appropriate height for the spray nozzles was the fact that the paths of fall for drops of the sizes most effective for fog dissipation (I00 to 200 microns) are very flat at wind velocities of 3 to $7 \mathrm{~m} / \mathrm{sec}$. Therefore, as the initial height is increased the spray invades more and more of the space which would otherwise be clear. After consideration of these factors a height of Io meters was selected as being appropriate for the nozzles of the experimental apparatus.

The required length of the suspended pipe line was determined by means of a simplified consideration of the effect of atmospheric turbulence, which restricts the extent of the cleared space in the direction of the wind by carrying in fog from the sides and top. It was shown in the second section of this paper that, for an ambient temperature of $20^{\circ} \mathrm{C}$, the condensation of 0.78 grams of water vapor per cubic meter of air, and the resultant temperature rise of $1.5^{\circ} \mathrm{C}$, would reduce the relative humidity to $87.5 \%$ as required for the prompt evaporation of the fog drops. This cleared air would be capable of evaporating $\mathrm{I} . \mathrm{I} 2 \mathrm{~g} / \mathrm{m}^{3}$ of water before becoming resaturated. Measurements at Round Hill have shown that an average dense fog contains about $0.2 \mathrm{~g} / \mathrm{m}^{3}$ of liquid water. ${ }^{1}$ The cleared air could therefore be mixed with I.12/0.2 $=5.6$ times as much fog before the evaporation of the fog drops would raise the relative humidity to $100 \%$. This is evidently the limiting condition which determines the length of the cleared space. It is now required to express this limiting distance as a function of the initial cross-section of the clearing and the rate of turbulent diffusion.

The rate of turbulent mixing varies over wide limits and depends on the nature of the terrain and the state of the weather. The problem was briefly investigated at Round Hill by observing the travel of smoke clouds at the location of the proposed apparatus under weather conditions similar to those occurring during fog. It was found that smoke issuing from a small source diffused in such a manner that the cross-section of the cloud in a direction normal to the wind had a width of about I $5 \%$ and a height of about Io\% of the distance traveled from the source. The smoke density appeared to be constant in a lateral direction and also in a vertical direction until the smoke reached the ground. It was assumed that the smoke was deflected by the ground in such a way that the smoke density near the ground was twice what it would have been in the absence of the ground.

Assuming that these rules apply equally well to the cleared air and that this air starts from the vertical area under the pipe line, it is readily possible to develop an expression for the concentration of cleared air at any point along the center line of the cleared space at the ground level.

\footnotetext{
1 See reference (Houghton and Radford 1938) at end of first section.
} 
Concentration of cleared air $=\int_{0}^{H} \int_{0}^{W} \frac{2 d h d w}{C C^{\prime} D^{2}}=\frac{2 H W}{C C^{\prime} D^{2}}$

where

$$
\begin{aligned}
& H \text { and } W=\text { the initial height and width of the clearing. } \\
& \begin{aligned}
C \text { and } C^{\prime} & =\text { the horizontal and vertical rates of diffusion as given above. } \\
D & =\text { distance from the apparatus in the direction of the wind. }
\end{aligned} \\
& D \text { must be greater than both } \frac{W}{C} \text { and } \frac{2 H}{C^{\prime}}
\end{aligned}
$$

As noted above, the limiting length of the cleared space corresponds to the point at which the cleared air has been mixed with 5.6 times its own volume of fog. That is, the limiting concentration is $1 / 5.6=0.1786$. It was desired to have the clearing about 500 meters long so that it would be considerably greater than the normal horizontal visibility in dense fog and also so that the clearing would reach prominent objects and thus make estimates of its extent easier. Inserting the given numerical values in Eq. ( $I$ ), it is found that for an initial height of Io meters the initial width must be about 33 meters to give a limiting distance of 500 meters.

Since the limiting concentration of the cleared air is equal to the liquid water content of the fog divided by the amount of water which the undiluted cleared air can evaporate, the length of the clearing is inversely proportional to the square root of the liquid water content of the fog. Thus, under the assumed conditions, the clearing would be about 700 meters long in a fog having a liquid water content of $0.1 \mathrm{~g} / \mathrm{m}^{3}$.

The cleared air diffuses outward as it proceeds down-wind thus tending to increase the cross-section of the cleared space. However, since the relative humidity of the cleared air steadily increases as a result of the evaporation of fog particles and the inward diffusion of saturated air, the time required for the evaporation of the fog drops which are carried in also increases. These two effects are in opposition and, from observation, the usual net result is a gradual increase of the cross-section of the cleared space as it travels down-wind until a maximum is reached at about 300 meters, beyond which the size decreases, finally becoming zero at the limiting distance which corresponds to I0o\% relative humidity in the cleared space.

\section{The Spray Nozzles}

The most important parts of the experimental apparatus itself are the spray nozzles which were specially developed for this application to provide drops of as uniform size as possible. The first nozzle used was a modification of a commercial type and consisted of two conventional "hollow cone" nozzles mounted axially and in opposition with a separation of about $\mathrm{I} \mathrm{cm}$. The impact between the two conical fluid sheets was found to produce fewer very large drops than when the nozzles were sprayed separately. Although the first successful tests of the fog dissipator were made with nozzles of this type they left much to be desired.

An intensive study of the fundamental factors affecting the formation of sprayed drops finally led to the development of the improved spray nozzle shown in Fig. I. This nozzle produces two axially opposed solid jets which intersect to form a circular fluid sheet in a plane perpendicular to their common axis. The metal shields which can be seen in the photograph serve to protect the fluid sheet from the disruptive action of the wind, the nozzle being mounted so that the wind comes from the side at the right of the photo- 
graph. The screen unit mounted on the down-wind side of the fluid sheet is a filter which removes a large number of the very small drops, which would otherwise be carried in to the cleared space.

\section{Quantity of Solution Required}

The method of computing the quantity of calcium chloride solution required for the dissipation of a given volume of fog is fully. discussed in the preceding section. Since the computations presented there were made on the basis of assumptions which are equally applicable to the present case, most of the results may be used directly.

With the assumption that all of the fog drops smaller than 50 microns in diameter should be completely evaporated within 20 seconds, it was found that a relative humidity of $87.5 \%$ would be required at an ambient temperature of $20.5^{\circ} \mathrm{C}$ and $84 \%$ at $10^{\circ} \mathrm{C}$. By considering both the removal of water vapor and the heat released by the condensation process, it was found that at $20.5^{\circ} \mathrm{C}$ the condensation of $0.78 \mathrm{~g}$ of water vapor per cubic meter would reduce the relative humidity to $87.5 \%$. Similarly, at $10^{\circ} \mathrm{C}$ the condensation of $0.77 \mathrm{~g} / \mathrm{m}^{3}$ of water vapor would reduce the relative humidity to $84 \%$. The computed quantities of water vapor condensed by one cc of solution sprayed then determine the quantity of calcium chloride solution required per cubic meter of fog. For the original opposed hollow-cone

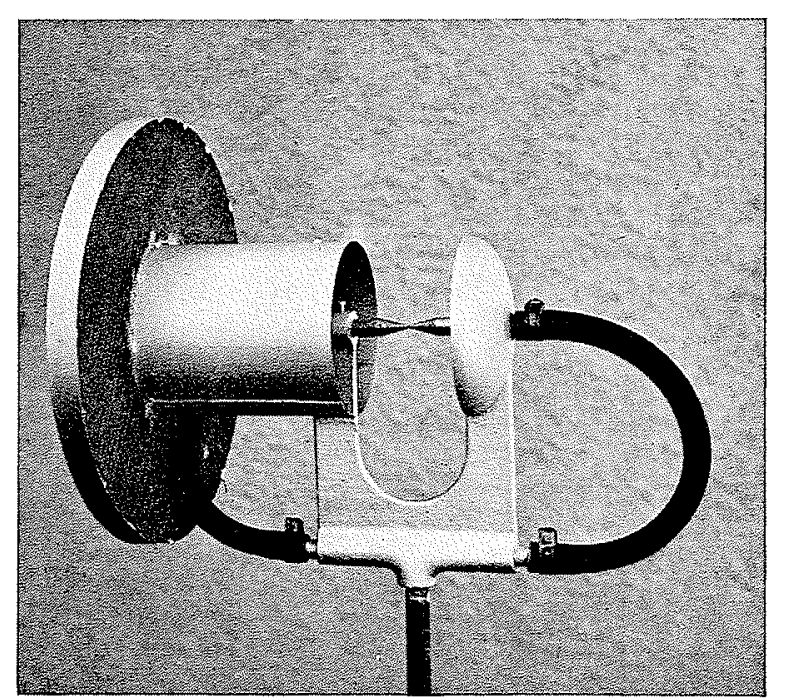

FIG. I.-A spray nozzel of the improved type. The installation of nozzles like this reduced the quantity of calcium chloride solution required for fog dissipation by more than $50 \%$. nozzles it was found that $6 . \mathrm{II} \mathrm{cc} / \mathrm{m}^{3}$ would be required at $10.5^{\circ} \mathrm{C}$ and $4.17 \mathrm{cc} / \mathrm{m}^{3}$ at $20.5^{\circ} \mathrm{C}$. For the improved nozzles the corresponding values are $2.54 \mathrm{cc} / \mathrm{m}^{3}$ at $10.5^{\circ} \mathrm{C}$ and $\mathrm{r} .92 \mathrm{cc} / \mathrm{m}^{3}$ at $20.5^{\circ} \mathrm{C} .{ }^{2}$

The cross-section over which the calcium chloride spray should be distributed by the proposed apparatus has already been fixed at $(33 \times 10=330)$ square meters. Since the wind velocities during fogs at Round Hill are frequently from 5 to $7 \mathrm{~m} / \mathrm{sec}$, the apparatus should be capable of treating roughly $2000 \mathrm{~m}^{3}$ of fog per second. The computations for this quantity of air presented in the preceding section may be used here directly.

With the original type of spray nozzle it was found that, for clearing $2000 \mathrm{~m}^{3} / \mathrm{sec}$, $12.2 \mathrm{~L} / \mathrm{sec}$ of solution would be required at $10.5^{\circ} \mathrm{C}$, and $8.3 \mathrm{~L} / \mathrm{sec}$ at $20.5^{\circ} \mathrm{C}$. At the optimum operating pressure $\left(50 \mathrm{lbs} / \mathrm{in}^{2}\right)$ these nozzles discharge about $50 \mathrm{cc} / \mathrm{sec}$. The number of nozzles required is thus from I 66 to 244 . Actually, 300 nozzles were installed. With the improved nozzles the quantity of solution required is $5 . \mathrm{I} \mathrm{L} / \mathrm{sec}$ at $10.5^{\circ} \mathrm{C}$, and $3.8 \mathrm{~L} / \mathrm{sec}$ at $20.5^{\circ} \mathrm{C}$. These nozzles discharge about $70 \mathrm{cc} / \mathrm{sec}$ at the proper operating pressure, so from 55 to 73 would be required. Actually, 70 were installed.

\footnotetext{
2 The solution is assumed to be saturated at the ambient temperature. At $20.5^{\circ} \mathrm{C}$ a saturated aqueous solution contains $42.8 \%$ anhydrous calcium chloride by weight and has a specific gravity of 1.429 . At $10.5^{\circ} \mathrm{C}$ the respective values are $39.6 \%$ and 1.395 .
} 
The Apparatus

Having determined the required dimensions and spraying capacity of the experimental fog dissipator as explained above, it was then possible to proceed with the actual installation of the necessary equipment. The apparatus was quite simple as is evident from Fig. 2 which shows the original arrangement utilizing spray nozzles of the opposed hollow-cone type. The elevated portion of the apparatus comprised two separate header pipes each 33 meters long, mounted side by side, and suspended Io meters above the ground. One of these pipes carried 100, and the other 200 evenly distributed nozzles. This arrangement permitted the amount of solution sprayed to be varied to suit the prevailing

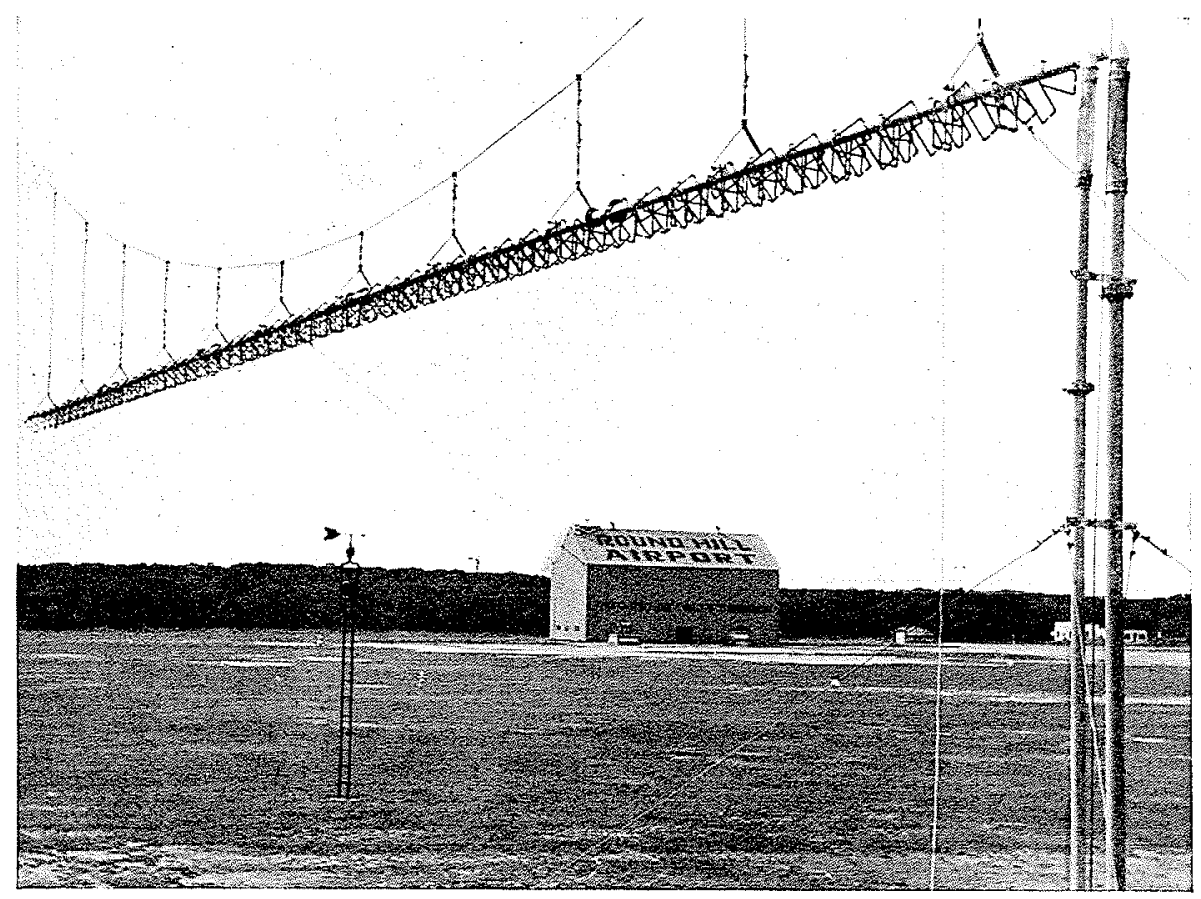

Frg. 2. The fog dissipator as it was originally installed, having a total of 300 opposed hollow cone spray nozzles mounted on two header pipes.

fog conditions. The header pipes were supported at eleven points from a steel suspension cable which was attached to a conveniently located steel radio tower and a large wooden flag pole. The tower and the pole were appropriately guyed for the large transverse loads.

The calcium chloride solution was stored in a large insulated tank which was equipped with thermostatically controlled heaters to prevent cooling of the solution below its saturation temperature. A smaller water storage tank was also provided for test purposes and for flushing the system after calcium chloride solution had been sprayed. A centrifugal pump delivered solution to the nozzles through vertical riser pipes which were coupled to the horizontal header pipes by means of short lengths of fire hose to allow for slight movements of the suspended nozzle structure.

When the improved opposed jet spray nozzles were subsequently installed, the smaller of the original header pipes was removed and two somewhat smaller pipes were added to permit appropriate mounting of 70 of the new nozzles. These two pipes were separated 
three feet vertically so that there would be no interference between nozzles. Each of the new nozzles was provided with a shut-off valve so that the number of nozzles spraying at one time could be conveniently varied. The appearance of the fog dissipator after the installation of the new nozzles is shown by Fig. 3 .

\section{Results of Fog Dissipation Tests}

Considerable attention was given to the problem of making adequate observations during the fog dissipation tests. Aside from a visual or photographic determination of the size and character of the clearing produced, the most important measurement was that of the amount of water vapor condensed from the air by the calcium chloride spray. At first an attempt was made to measure the water vapor content of the air after it had

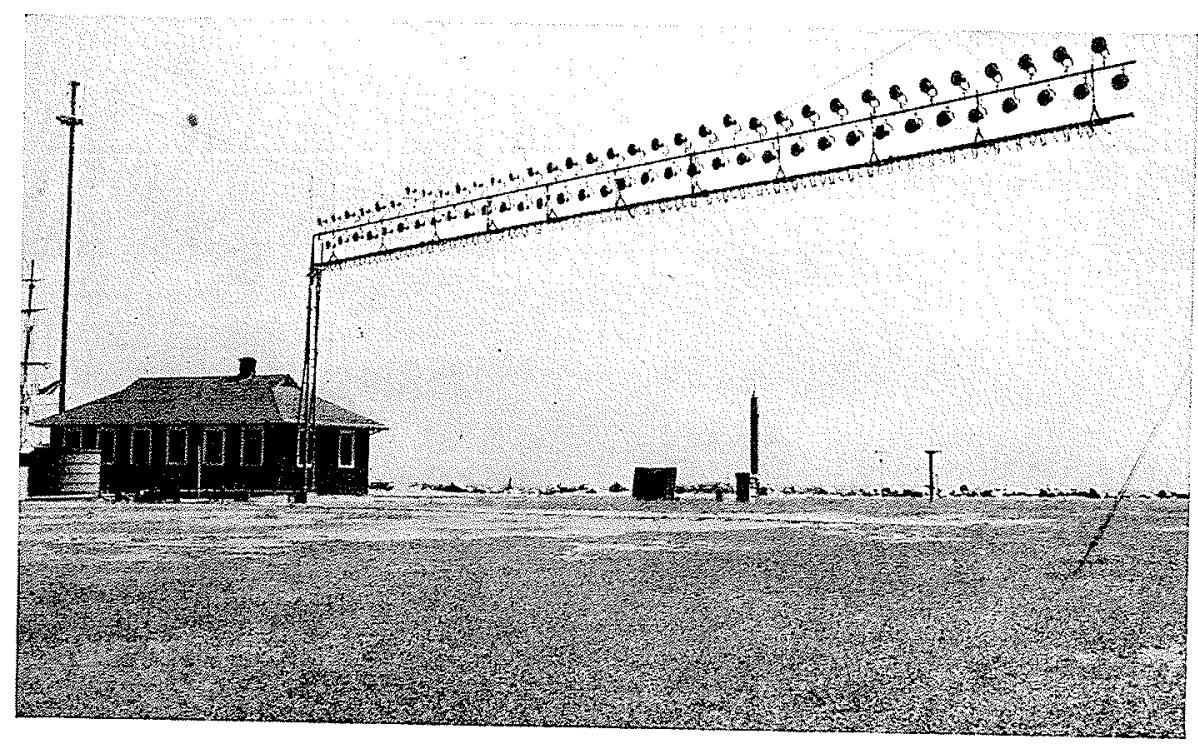

FIG. 3. - The fog dissipator after the installation of 70 improved nozzles of the type shown in Fig. I.

passed through the spray curtain, but this was rendered very difficult by the presence of fine calcium chloride spray in the region where it was desired to make the measurements. It was found that it was much more satisfactory to determine the amount of water vapor removed by collecting samples of the sprayed solution at a number of points on the ground in shallow pans equipped with covers which could be tightly closed as soon as sufficiently large samples had been obtained. The total amount of water vapor condensed could then readily be determined from the area of the pans and the concentration and amount of the solution caught in each.

During each fog dissipation test measurements were also made of the duration of the test, the total amount of solution sprayed, the quantity of solution lost as drip from the nozzle structure, the horizontal visibility, the air temperature, the wind direction, and the wind velocity. In order to eliminate effects of sudden changes in fog conditions and also to keep the cost of the experiments at a minimum, it was desirable to make the observations as quickly as possible. Tests were usually completed within 4 to 8 minutes. When possible, both the size of the fog particles and the liquid water content of the fog were also measured immediately before and after each test. 
Nine tests were made with the fog dissipation apparatus described over a period of two and one-half years, both with the original spray nozzle installation and, more recently, with the improved nozzles. Tests were conducted under various wind conditions and for air temperatures ranging from $4^{\circ}$ to $20^{\circ} \mathrm{C}$. There was only one test during which a definite clearing was not produced and this failure was caused by a sudden shift in wind direction while the test was in progress. In general it was observed that the air temperature had little effect on the results and that the best clearings were produced when the wind was steady and had a velocity of $4 \mathrm{~m} / \mathrm{sec}$ or more. Under typical conditions a cleared space was formed which was about 600 meters in length, from 30 to 50 meters wide and at least I 5 or 20 meters high. The height of the cleared space could be determined only when the clearing intersected some large object such as a house. In every case when this occurred the entire height of the object was visible so that the vertical extent of the clearing may well have been considerably greater than the estimate based on the height of the observed object.

Several attempts were made to obtain photographic records of clearings produced by the fog dissipator, but the results were rather unsatisfactory. Since most of the tests were made late in the day and in fogs accompanied by overcast skies, the lighting conditions were usually very poor, resulting in a lack of contrast and detail in the photographs. Except in those cases when stereoscopic exposures were made the perspective was also poor because of the restricted view obtained down the clearing. In spite of these difficulties it was decided to include the photographs shown in Fig. 4, which were taken during

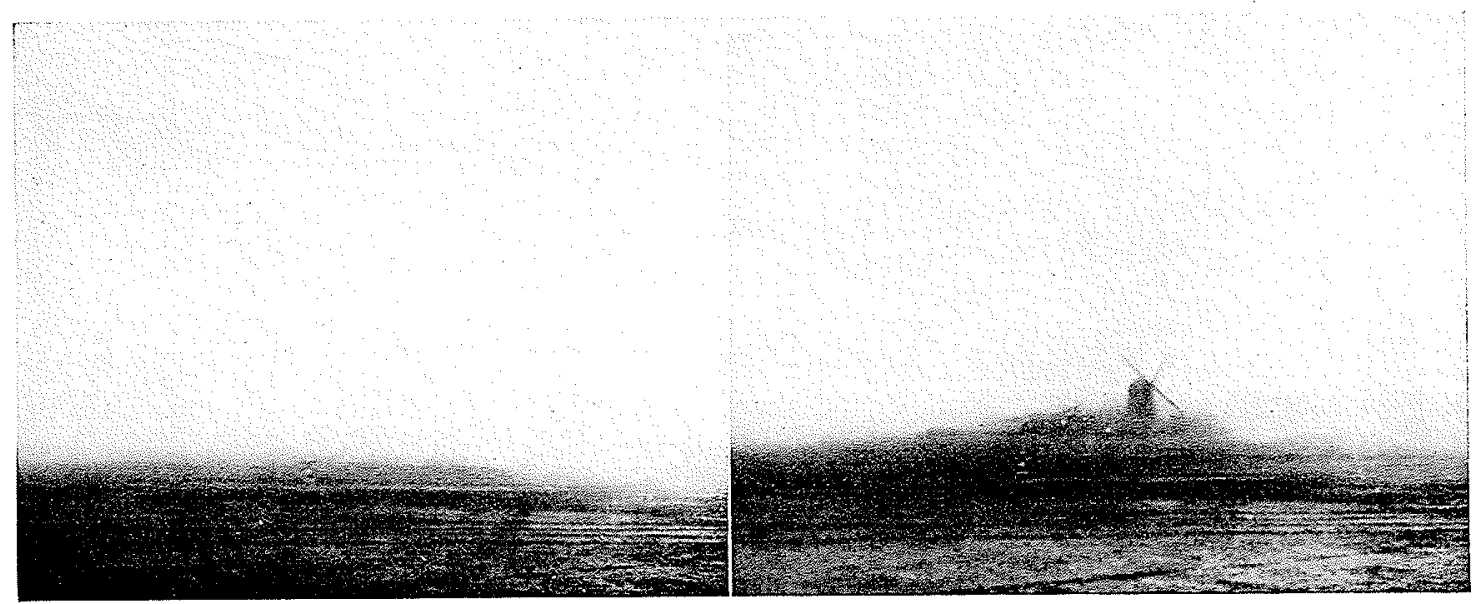

FIG. 4- - Photographs taken immediately before and during a fog dissipation test. The windmill, which has an overall height of about 20 meters, is about $3 c 0$ meters away from the camera and 400 meters away from the fog dissipator. The horizontal visibility was about $250 \mathrm{~m}$ before the test and about $750 \mathrm{~m}$ looking down the clearing during the test.

a typical fog dissipation test. Some additional detail and contrast have been lost in the reproduction process, but a large windmill is plainly visible in the clearing. This windmill is located 400 meters distant from the fog dissipator, and the height of the tops of the arms is about 20 meters. In the original photograph a fence over 500 metres from the dissipator was also visible, but a large house 750 meters away, which was visible to the operator of the camera, did not show at all on the photograph.

Two tests, one made with the original nozzle installation and the other made after the installation of the improved spray nozzles, have been selected as typical examples of 
the results which were obtained. The first test to be considered was made on July I 8, I935 in a fog in which the horizontal visibility was about 150 meters. There was a south-west wind having a velocity of $6.2 \mathrm{~m} / \mathrm{sec}$ and the air temperature was $20.4^{\circ} \mathrm{C}$. The visibility down the cleared path was about 700 meters. The test lasted 290 seconds and solution was sprayed at the rate of $9.8 \mathrm{~L} / \mathrm{sec}$ exclusive of that lost as "drip." At a point 360 meters from the apparatus the width of the clearing was about 35 meters and the height was at least 20 meters. Samples of the sprayed solution were collected at the ground level in nine pans which were distributed over a total distance of about Ioo meters from the apparatus in the direction of the wind. The results of the measurements of the quantities and the concentrations of these samples are presented in Fig. 5. The ordinates of the "Solution sprayed" curve give the quantity of solution collected at each point based on the initial concentration of the solution. The area under this curve, when multiplied by the width of the spray curtain measured normal to the wind direction, gives the total amount of solution sprayed. In this case it is found to be $10.0 \mathrm{~L} / \mathrm{sec}$ as compared to the actual value of 9.8 $\mathrm{L} / \mathrm{sec}$ which was determined by measuring the rate of flow from the solution tank and subtracting the solution lost as drip.

This result is of no particular importance in itself but it is an indication of the precision of the results obtained

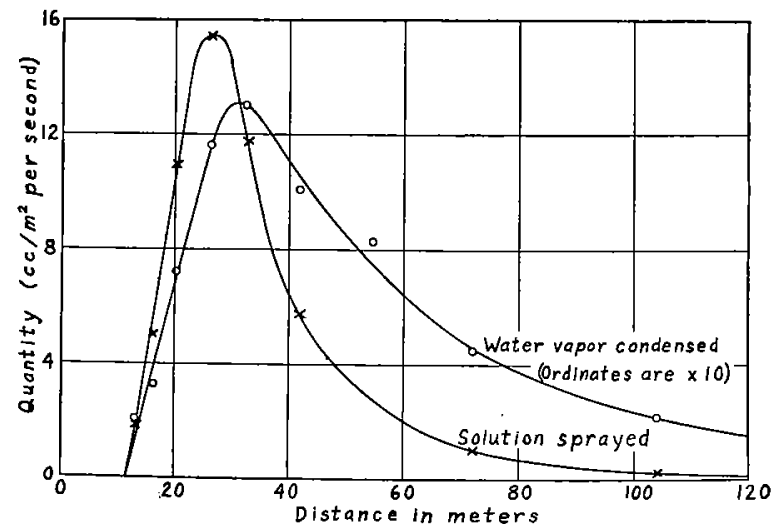

Fig. 5.-Results obtained from the samples of sprayed solution collected in pans at the ground level during the fog dissipation test of July 18 , I 935 .

from the collecting pans. The ordinates of the "Water vapor condensed" curve (Fig. 5) represent the quantity of water necessary to dilute the original solution to the observed concentrations of the collected samples. The area under this curve multiplied by the width of the spray curtain gives the total amount of water vapor condensed and in this case it is found to be $\mathrm{I} .68 \mathrm{~L} / \mathrm{sec}$. The relative humidity of the air after passing through the spray can be readily determined from this figure and the mass and initial temperature of the air passing through the spray curtain. ${ }^{3}$ It is found to be about $87 \%$. The quantity of water vapor condensed per cubic centimeter of solution sprayed is $1.68 / 10.0=0.168$ which is somewhat lower than the computed value of 0.187.

A typical fog dissipation test using the improved spray nozzle installation was made on January I4, I937. The horizontal visibility was 250 meters, the temperature was $7.2^{\circ} \mathrm{C}$, and the wind was south-southwest with a velocity of $7.0 \mathrm{~m} / \mathrm{sec}$. Calcium chloride solution was sprayed for 390 seconds at a net rate of $4.85 \mathrm{~L} / \mathrm{sec}$. A clearing was maintained of such length that a large house 750 meters away was clearly visible. The cleared space was from 30 to 50 meters wide and at least 20 meters high at a distance of 500 meters from the apparatus. As in all tests made with the improved spray nozzle installation, there was much less fine spray in the clearing than when the original nozzles were used. This was probably largely owing to the screen filters, shown in Fig. I, which remove a large portion of the fine drops immediately after they are formed.

The data obtained from samples of the sprayed solution collected during this test

${ }^{3}$ See Eqs. (IO) and (II) in the second section. 
are presented in Fig. 6. It is interesting to compare the locations of the maxima of the curves in Figs. 5 and 6 . This comparison brings out the fact that the bulk of the solution reaches the ground farther from the apparatus in the case of the improved spray nozzles, a further indication that these nozzles produce much fewer large drops than the nozzles of the original type. From the areas under the curves of Fig. 6 it is found that the amount of water vapor condensed for each cubic centimeter of solution sprayed is $0.273 \mathrm{cc}$. A computed value is not available for a temperature of $7.2^{\circ}$ for comparison, but the value for $10.5^{\circ}$ is $0.303 \mathrm{cc}$ and it is known that it would be somewhat less at $7.2^{\circ} \mathrm{C}$. From the observed rate of condensation of water vapor, and the wind velocity, it is found that the relative humidity of the air after passing through the spray was about $89 \%$.

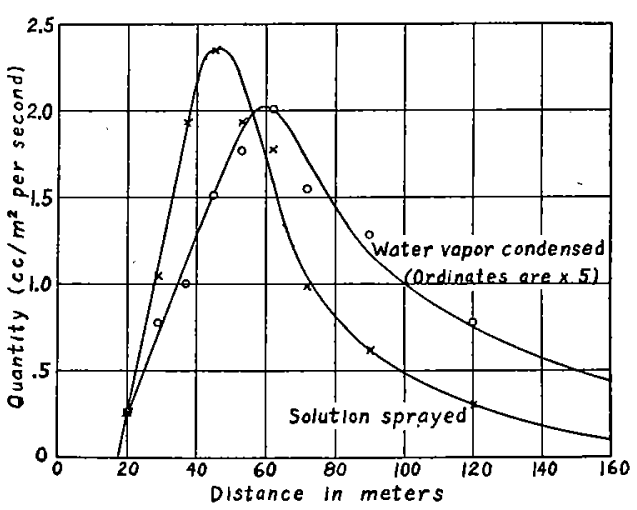

FIG. 6.- Results obtained from the samples of sprayed solution collected in pans at the ground level during the fog dissipation test of January I4, I937.

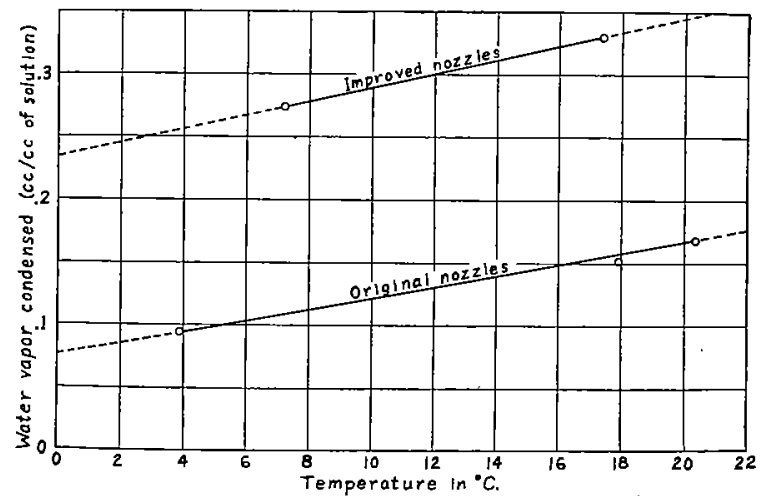

FIG. 7.-The quantity of water vapor actually condensed by a unit volume of sprayed calcium chloride solution as a function of the air temperature and for both types of spray nozzles.

To permit a more satisfactory comparison of the computed and experimental values of the amount of water vapor condensed by a unit volume of sprayed solution, the experimental ratios have been plotted against air temperature in Fig. 7. Computed values are available for $10.5^{\circ} \mathrm{C}$ and $20.5^{\circ} \mathrm{C}$, so by reading the corresponding ordinates from the experimental curves a proper comparison can be made. The following tabulation shows that in all cases the agreement is as good as could be expected.

\begin{tabular}{c|c|c|c|c}
\hline \hline & \multicolumn{2}{|c|}{ Original SPRay Nozzles } & \multicolumn{2}{|c}{ IMproved SPRay NozzLes } \\
\cline { 2 - 3 } & Computed & Observed & Computed & Observed \\
\hline Air. temp. & 0.126 & 0.122 & 0.303 & $0.29 \mathrm{r}$ \\
20.5 & 0.187 & 0.168 & 0.405 & 0.350 \\
\hline
\end{tabular}

\section{Conclusion}

The tests described in this section have conclusively demonstrated the practicability of the local dissipation of natural fog by means of a sprayed solution of calcium chloride. The particular type of apparatus described was selected as the most suitable for the initial tests of the method at Round Hill. It is recognized that this particular form of apparatus has limitations which may restrict its practical application elsewhere. From the discussion in this paper it is evident that the fixed equipment described can be used 
only when the fog is accompanied by a wind of nearly constant direction. When operation is attempted in light winds, which are usually subject to large fluctuations both in velocity and direction, the cleared space is rapidly filled in with fog. At Round Hill it has been found that a minimum wind velocity of about $3 \mathrm{~m} / \mathrm{sec}$ is required for the satisfactory operation of the apparatus. Since the filling-in of the cleared space is an edge effect a larger installation would probably operate satisfactorily at somewhat lower wind velocities, but in any event there is a definite limit. Apparatus of the type described cannot readily be made portable and its size makes it a rather serious obstruction for some applications, notably at airports.

One disadvantage which is inherent in the spray method of fog dissipation is the relatively wide spatial distribution of sprayed drops which results, particularly when there is a considerable wind velocity. If it comprised no drops smaller than about roo microns the spray would all fall within fairly well-defined limits, but since a certain number of small drops is normally present some of the spray will inevitably be carried in to the clearing. By the use of the wire screens on the improved spray nozzles the number of these small drops has been so reduced that their effect on the visibility in the cleared space is negligible. However, any object remaining in the cleared space for an appreciable period becomes coated with droplets of calcium chloride solution, which is corrosive to certain metals, particularly to aluminum and its alloys. Corrosive action can be halted by flushing the exposed parts with a solution of any soluble carbonate such as "washing soda." This might of ten be accomplished by spraying such a soda solution through the nozzles immediately after the calcium chloride solution had been sprayed.

Consideration has been given to the possibility of reducing the corrosive effect by the addition of corrosion inhibitors to the calcium chloride solution. It has been found that the addition of an amount of bichromate sufficient to give the typically orange bichromate coloration (about $2 \%$ by weight) practically eliminates the corrosive action on aluminum and its alloys. The corrosion of iron, steel, and magnesium is also reduced so that it is less than that produced by sea water. It is believed that the use of this corrosion inhibitor, and the washing of exposed parts with a soda solution, would practically eliminate corrosion difficulties.

The development of fog dissipation apparatus which does not have some of the practical limitations of the suspended spray nozzle type of equipment described in this paper is now well advanced. An experimental unit has been built comprising a large blower and a group of opposed jet nozzles so arranged that the sprayed drops are carried along in the air blast created by the blower. The unit is entirely self-contained and mobile and is much smaller than the suspended nozzle installation. When this "blower-spray" unit is operated in fog accompanied by extremely low wind velocity, or a calm, it is moved or rotated to distribute the calcium chloride spray throughout the entire volume to be cleared. With higher wind velocities the spray is distributed in a general cross-wind direction, forming a spray curtain similar to that provided by the operation of the suspended spray nozzle apparatus. Although the new unit does not distribute the sprayed drops in quite so satisfactory a manner as the elevated nozzle array when the latter operates under favorable wind conditions, its greater flexibility should more than make up for that slight disadvantage.

Naturally many new problems have arisen in connection with the development of the blower-spray equipment, but these cannot be discussed here. It is believed, however, that solutions to most of these problems are in sight. 


\title{
IV. A NEW TYPE OF APPARATUS FOR THE DISSIPATION OF FOG BY MEANS OF FINE HYGROSCOPIC PARTICLES
}

\author{
By H. G. HOUGHTON AND W. H. RADFORD
}

Although the spray-type fog dissipator described in the preceding section operated in an entirely satisfactory manner during appropriate fog conditions, and thereby demonstrated the feasibility of dissipating fog by means of hygroscopic particles, this particular method has certain disadvantages which would limit its general practical application. The most fundamental drawback is that the spray is distributed over a considerable area. Some of the space obscured by the falling spray curtain would otherwise be partly cleared air. Since it has not been found possible to avoid the formation of an appreciable number of very small drops by spray nozzles, the hygroscopic curtain does not have a sharply defined down-wind boundary and a certain amount of fine calcium chloride spray is carried in to the clearing. The presence of this spray is generally undesirable, even though methods have been devised for practically eliminating its corrosive action.

Moreover, the particular type of apparatus which has been described is evidently operable only when the fog is accompanied by a wind having a direction approximately normal to the header pipe. In practice it has been found that a satisfactory clearing is not produced if the wind velocity is less than about $3 \mathrm{~m} / \mathrm{sec}$ because the direction of light wind is subject to such large variation that the cleared space is rapidly filled in. Fogs accompanied by light winds are very common in some sections, and only rarely will the prevailing fog wind direction and velocity be as constant as at Round Hill. The suspended spray nozzle dissipator is not readily made mobile so that its location and orientation may be changed to suit existing wind conditions. It also constitutes a considerable obstruction which would be particularly serious in the case of an airport installation.

Disadvantages such as the foregoing have been largely overcome in the modified fog dissipator to be described in this section. The most significant feature of the improved dissipator is that it is constructed in the form of a large tunnel and the hygroscopic material is confined entirely within it. Only cleared and partly dried air is discharged and the clearing effect starts at the apparatus itself, instead of beyond an external spray curtain as with the original dissipator. This desirable arrangement is made possible by the use of very fine hygroscopic particles which will absorb a sufficient quantity of water vapor in less than one second, as compared with about 20 seconds for the relatively large drops which must be used in the spray method. Since the fine particles will not be removed by gravity, it is necessary to provide a mechanical means for separating them from the dried air.

The general arrangement of a unit of this type is shown in Fig. I. The fine hygroscopic particles are uniformly distributed throughout the air as it enters. In the fraction of a second required for the air to pass the length of the apparatus the particles will have absorbed their quota of water vapor and will then be removed from suspension by the eliminator, which is somewhat similar to those used in air conditioning equipment. The fan draws air through the apparatus at a suitable rate and also performs the very important function of properly distributing the dehumidified discharge air. By virtue of the blower, this type of apparatus can be operated in a calm as well as in a steady wind. It should also be noted that since the hygroscopic material is confined ${ }^{1}$ to the apparatus it can be reclaimed.

\footnotetext{
1 The extent to which the material is confined obviously depends upon the collection efficiency of the eliminator.
} 
From the results of numerous tests with the spray type of fog dissipator and confirmatory computations, it is known that fog must be cleared at the rate of 2000 cubic meters per second to maintain a clearing of useful size. It was found that this could be satisfactorily accomplished by reducing the relative humidity to about $87.5 \%$. Due to the absence of an external spray curtain with the new method, it is believed that a some-

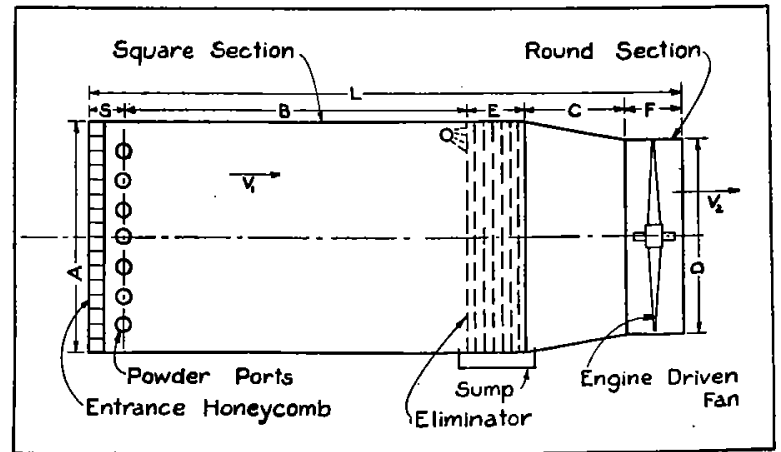

FIG. I.-Diagram indicating the essential features of the improved fog dissipator. The following summary gives the principal dimensions of the experimental model, and both the dimensions and operating conditions of the suggested full-sized fixed and mobile units.

\begin{tabular}{|c|c|c|c|c|}
\hline \multirow{2}{*}{ Quantity } & \multirow{2}{*}{ UNITS } & \multirow{2}{*}{$\begin{array}{c}\text { MODEL } \\
\text { APPARATUS }\end{array}$} & \multicolumn{2}{|c|}{ Full Sized Apparatus } \\
\hline & & & Fixed & Mobile \\
\hline $\begin{array}{c}\mathrm{A} \\
\mathrm{S} \\
\mathrm{B} \\
\mathrm{E} \\
\mathrm{C} \\
\mathrm{F} \\
\mathrm{D} \\
\mathrm{L} \\
\mathrm{A}^{2} \\
\text { Flow } \\
\text { Exit R.H. } \\
\text { Action time } \\
\text { Powder rate } \\
\text { Powder rate } \\
\mathrm{V}_{1} \\
\mathrm{~V}_{2} \\
\text { Air power } \\
\text { Engine power } \\
\text { Temp. rise } \\
\text { Water vapor } \\
\text { removed }\end{array}$ & $\begin{array}{c}\mathrm{m} \\
\mathrm{m} \\
\mathrm{m} \\
\mathrm{m} \\
\mathrm{m} \\
\mathrm{m} \\
\mathrm{m} \\
\mathrm{m} \\
\mathrm{m}^{2} \\
\mathrm{~m}^{3} / \mathrm{sec} \\
\% \\
\mathrm{sec} \\
\mathrm{g} / \mathrm{m}^{3} \\
\mathrm{~kg} / \mathrm{sec} \\
\mathrm{m} / \mathrm{sec} \\
\mathrm{m} / \mathrm{sec} \\
\mathrm{hp} \\
\mathrm{hp} \\
\mathrm{deg} . \mathrm{C} \\
\% \\
\%\end{array}$ & $\begin{array}{l}1.0 \\
1.0 \\
4.0 \\
1.0 \\
0.7 \\
1.0 \\
0.8 \\
8.7 \\
1.0\end{array}$ & $\begin{array}{r}5.8 \\
1.0 \\
12.0 \\
1.0 \\
3.0 \\
1.0 \\
5.3 \\
18.0 \\
33.0 \\
400 \\
50 \\
1.0 \\
5.5 \\
2.2 \\
12.0 \\
20.0 \\
319 \\
456 \\
6.5 \\
\\
27.5\end{array}$ & $\begin{array}{r}5.2 \\
1.0 \\
7.5 \\
1.0 \\
2.0 \\
1.0 \\
4.5 \\
12.5 \\
27.0 \\
400 \\
50 \\
0.5 \\
10.0 \\
4.0 \\
15.0 \\
30.0 \\
565 \\
807 \\
7.8 \\
\\
22.5\end{array}$ \\
\hline
\end{tabular}

what longer time can be allowed for the evaporation of the fog particles. Accordingly the proposed new apparatus has been designed to reduce the relative humidity in 2000 cubic meters of fog per second to only $90 \%$.

It is apparent that a tunnel of inordinately large cross-section would be required to handle $2000 \mathrm{~m}^{3} / \mathrm{sec}$ at any reasonable air velocity. This difficulty may be overcome by removing the required total amount of water vapor from a fractional part of the total quantity of air to be cleared, and subsequently mixing this dried air with the remainder. 
The fraction of the air which must be passed through the drying apparatus depends on the proportion of water vapor which can be removed from a unit volume of saturated air. This, in turn, depends to a considerable extent on the particular hygroscopic material used. Dry, powdered calcium chloride was selected as the most suitable material because it is very hygroscopic, relatively inexpensive, non-toxic and commercially available in suitable form. Since, in use, the particles of calcium chloride tend to become coated with a film of a saturated solution before they are completely dissolved, it is not possible to reduce the relative humidity below the equilibrium value for a saturated solution (about $35 \%$ ) unless a very large quantity of powder is used. The results of an experimental study, which will be described presently, indicate that the practical economic limit of the final relative humidity is actually about $50 \%$.

A relative humidity of $90 \%$ can evidently be produced in $2000 \mathrm{~m}^{3}$ of fog by reducing the relative humidity to $50 \%$ in $400 \mathrm{~m}^{3}$ and then mixing this uniformly with the remaining $\mathrm{I} 600 \mathrm{~m}^{3}$. Thus a unit for clearing fog at the rate of $2000 \mathrm{~m}^{3} / \mathrm{sec}$ need have an air capacity of only $400 \mathrm{~m}^{3} / \mathrm{sec}$, which can be handled by a tunnel of entirely reasonable dimensions as will be shown in detail later.

\section{Preliminary Computations}

The most important information required for the design of the proposed fog dissipator, aside from the quantity of air which must be handled, is the amount of calcium chloride powder needed and the time during which it must remain in the air to produce the necessary reduction in the relative humidity. This time will be referred to hereafter simply as the "action time."

From the investigations in connection with the dissipation of fog by means of a saturated calcium chloride solution spray, ${ }^{2}$ it was known that the time $T$ required for a spherical hygroscopic particle to become diluted by condensation is given by the following integral:

$$
T=\frac{A^{2}}{8 k} \int_{d_{1}}^{d_{2}} \frac{\mathrm{I}}{D-D_{0}} d(a / A)^{2} .
$$

where

$$
\begin{aligned}
A & =\text { initial drop diameter. } \\
a & =\text { drop diameter at time } t . \\
k & =\text { diffusion coefficient of water vapor into air. }
\end{aligned}
$$

$D_{0}$ and $D=$ respectively the water vapor densities at the surface of the drop and in the surrounding atmosphere.

$d_{1}$ and $d_{2}=$ respectively the initial and final drop dilutions in terms of the corresponding values of $(a / A)^{2}$.

To evaluate this integral it is necessary to have the term $\mathrm{I} /\left(D-D_{0}\right)$ as a function of $(a / A)^{2}$, which is in turn a function of the dilution.

In the particular case under consideration, $D$ is a function of the total amount of water vapor removed, while $D_{0}$ is a function of both the concentration of the particle and its temperature. The particle temperature can be determined closely by equating the heat of condensation plus the heat of solution to the heat lost by conduction, but unfortunately the relation between $D_{0}$ and the drop temperature and concentration cannot

2 These investigations have been fully discussed in the two preceding sections. 
be expressed analytically in such a manner as to permit the integration to be performed. It is therefore impracticable to obtain a direct solution of equation (I).

However, by assuming that all of the calcium chloride particles are of the same.initial size and concentration, so that $D$ is a function only of $(a / A)^{2}$, it has been possible to make a step by step solution for various quantities of calcium chloride powder per unit volume of air. The computations also assumed that the salt particles are spherical and that they remain homogeneous throughout the dilution process. Actually, the dry particles

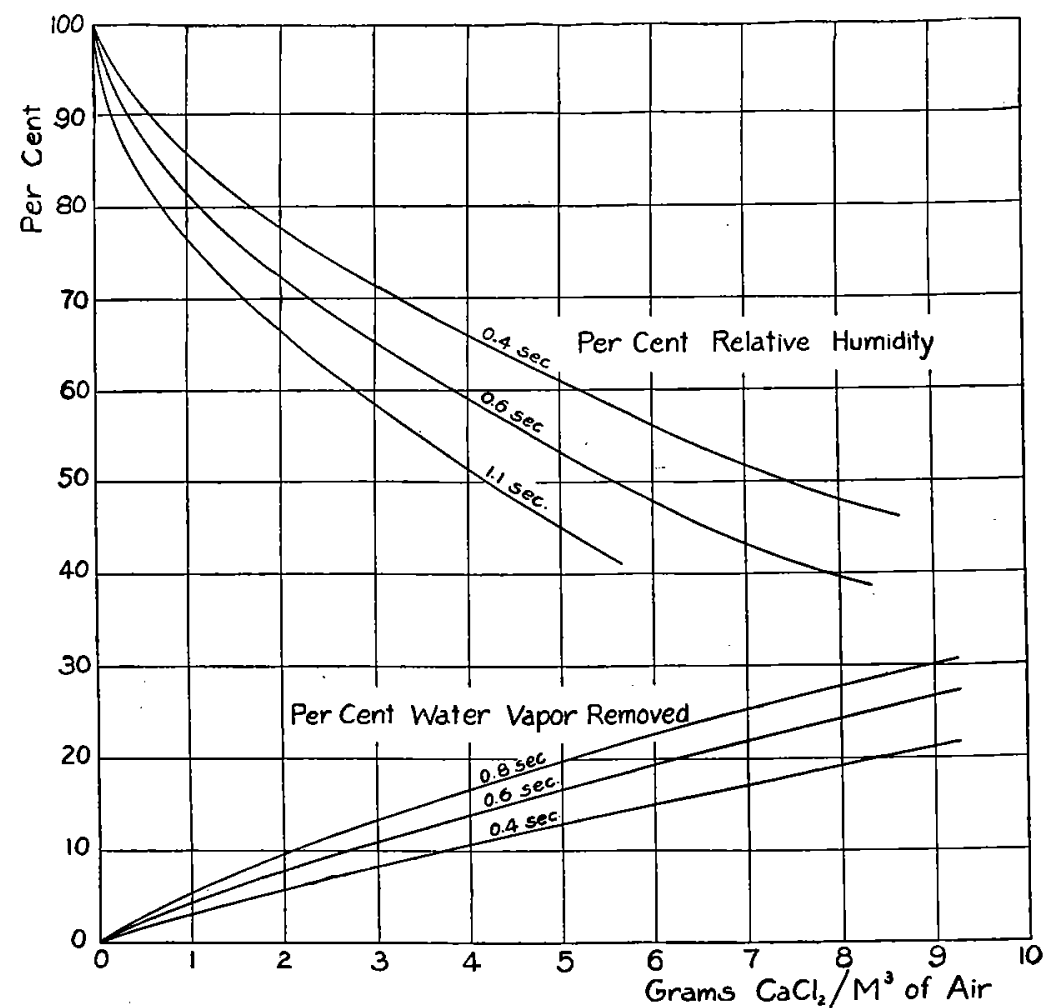

Fig. 2.-Results of the preliminary computations showing both per cent relative humidity of the exit air and the percentage of water vapor removed as functions of the powder rate, expressed in grams of $\mathrm{CaCl}_{2} / \mathrm{m}^{3}$ of air. Curves were computed for various action times, using equation ( 1 ). The entering air was assumed to be saturated at $20^{\circ} \mathrm{C}$. It was also assumed that all of the powder particles were initially spheres 40 microns in diameter, and that they remained homogeneous throughout the dilution process.

are not initially spherical, but it has been found by experience that the assumption of spherical particles does not introduce a very large error. There is reason to believe that the particles become coated with a film of a saturated solution before they dissolve completely; hence the second assumption may not be valid.

The most serious limitation of the computations is that they apply only to particles of a uniform size. Although it might be possible to obtain a powder which satisfies this condition, by a proper grinding and sorting process, it is desirable for economic reasons to use the available commercial calcium chloride powder which comprises particles of a wide range of sizes. Approximate computed results for this commercial powder were ob- 
tained by selecting an appropriate average particle diameter. The actual particle size distribution of the powder was determined by suspending a sample in kerosene and making microscopic measurements of the individual particles. It was found that the particles ranged in "diameter" from I to 60 microns, the greatest proportion of the powder being represented by the size group centered at 25 microns. However, this diameter is not a suitable average for use in the computations because the dilution of the smaller particles is limited by the low final relative humidity and they therefore cannot remove enough water vapor to compensate for the reduced amount condensed by the particles larger than 25 microns.

After a consideration of this effect and the particle size distribution data, which has a broad maximum, it was decided that 40 microns represented the best average value. The results of the computations for a powder comprising only 40 micron particles are presented in Fig. 2, in the same form as the experimental data which appear later. One of the most interesting points brought out by these results is the relatively small difference in final relative humidity caused by a considerable change in the action time. This is quite important since the action time largely determines the dimensions of the unit. From Fig. 2 it appears that an exit relative humidity of $50 \%$ could be obtained with an action time of 0.5 second by using about 6.5 grams of powder per cubic meter of air. This would result in the removal of approximately $\mathrm{I} 8.5 \%$ of the water vapor. The remainder of the relative humidity reduction would be due to the heats of condensation, solution and dilution.

From Eq. ( $\mathrm{I}$ ) it is evident that the action time is proportional to the square of the initial particle diameter. Hence a considerable reduction in the required time, and therefore in the dimensions of the unit, could be obtained by the use of smaller particles. The practical lower limit of particle size is determined by the cost of producing the powder and by the fact that the eliminator will not remove extremely small particles. The results to be expected from the use of particles of a uniform diameter other than 40 microns may be determined from Fig. 2 by correcting for the change in action time.

\section{Construction of an Experimental Model}

Since the complexity of the processes involved prevented exact calculation of the performance of the proposed fog dissipation apparatus, it was decided to resort to experimental methods of determining the data required in the design of a full-sized unit. It was decided that the necessary experiments could be most conveniently performed on a small working model. It also appeared that a model study would facilitate the development of the necessary powder distributing and collecting equipment and possibly reveal any unforeseen difficulties in the practical application of the method.

In determining the proportions of the experimental model an effort was made to provide a unit which would be reasonably small and easy to control yet which, at the same time, would be large enough to minimize any scale effect and to permit the desired measurements to be made with convenience and accuracy. The more important dimensions were selected on the basis of the results of the calculations already described. It was finally decided that the requirements could be suitably met by a model having the dimensions and essential features indicated by the diagram in Fig. I. The body of this unit consisted of a sheet metal tunnel six meters long and with a cross-section one meter square. Within the tunnel, a short distance from the intake end, there was mounted an array of four discharge ports through which powdered calcium chloride could be intro- 
duced by means of a pneumatic conveying system. This system included a small calibrated screw conveyor for regulating and measuring the powder feed rate. The conveyor, which was arranged so that it could be conveniently driven at any one of a number of different speeds, was mounted at the bottom of a powder hopper and discharged directly into the intake of the forge-type blower of the pneumatic system. Near the discharge end of the tunnel there was an eliminator for removing the spent calcium chloride particles from the air stream. Immediately below the eliminator there was a sump which normally contained a quantity of calcium chloride solution which was circulated, by means of a small gear pump, through flooding nozzles mounted near the top of the eliminator to assist in the collection of solid particles and their subsequent drainage to the sump. The eliminator unit used in the first tests consisted simply of a succession of coarse mesh wire screens. Subsequently an improved eliminator was substituted for reasons which presently will be apparent. Immediately beyond the eliminator the square tunnel converged to a short circular section (See Fig. I) in which was mounted a four-bladed propeller-type fan 0.8 meter in diameter. This fan unit discharged directly into the atmosphere. The entire model was mounted out-of-doors about one meter above the ground, with the intake end facing the direction from which the prevailing wind blew. In order to obtain reasonably uniform air velocity over the cross-section of the tunnel during operation with crosswinds, it was necessary to equip the intake end with a short honeycomb structure as indicated in Fig. I.

The measuring equipment used with the model included conventional pitot tubes and manometers for determining velocity of flow and static pressure drops, a conventional aspiration psychrometer for measuring the relative humidity of the inlet air and a special aspiration psychrometer for similar observations on the outlet air. Since the removal efficiency of the eliminator was always less than 100\%, the outlet air contained a number of entrained particles of calcium chloride solution. Wet and dry bulb thermometers directly exposed to the outlet air soon would have become coated with calcium chloride solution which would have caused erroneous indications. To prevent this a. highly efficient screen-type eliminator was attached to the intake of the psychrometer and was

oriented at right angles to the exit air stream so that most of the entrained particles could not enter because of their inertia. As a further precaution both thermometers were thoroughly cleaned between readings. Several eliminator units were provided so that a dry one could be substituted as soon as one collected enough calcium chloride to appreciably modify the vapor pressure of the entering air. Experiments indicated that this special psychrometer gave correct readings in air containing a much greater quantity of suspended calcium chloride than was ever encountered in the model tests.

\section{Measurements With the Model}

The principal objectives of the measurements with the model of the proposed fog dissipator were the determination of the amount of calcium chloride powder and the action time required to produce a given outlet relative humidity. Tests were conducted either in fog or at times when the ambient relative humidity was greater than $95 \%$. The test procedure is apparent from the preceding description of the model and its auxiliary equipment. The action time was varied by changing the flow velocity, which was controlled by the fan speed. The average flow velocity was carefully determined from traverse readings with a pitot tube made immediately before and after each test. As previously indicated, the powder feed rate was controlled and measured with the small 
screw conveyor, which was calibrated to determine its discharge rate as a function of speed. The wet and dry bulb temperatures of the inlet and outlet air were determined with the psychrometers already described. In conducting each test, care was taken to operate the model long enough for equilibrium conditions to be attained.

The essential results of the model tests are summarized by the curves in Figs. 3 and 4. The apparent scattering of some of the plotted data is due partly to experimental errors, but largely to unavoidable variations in ambient conditions between tests. One of

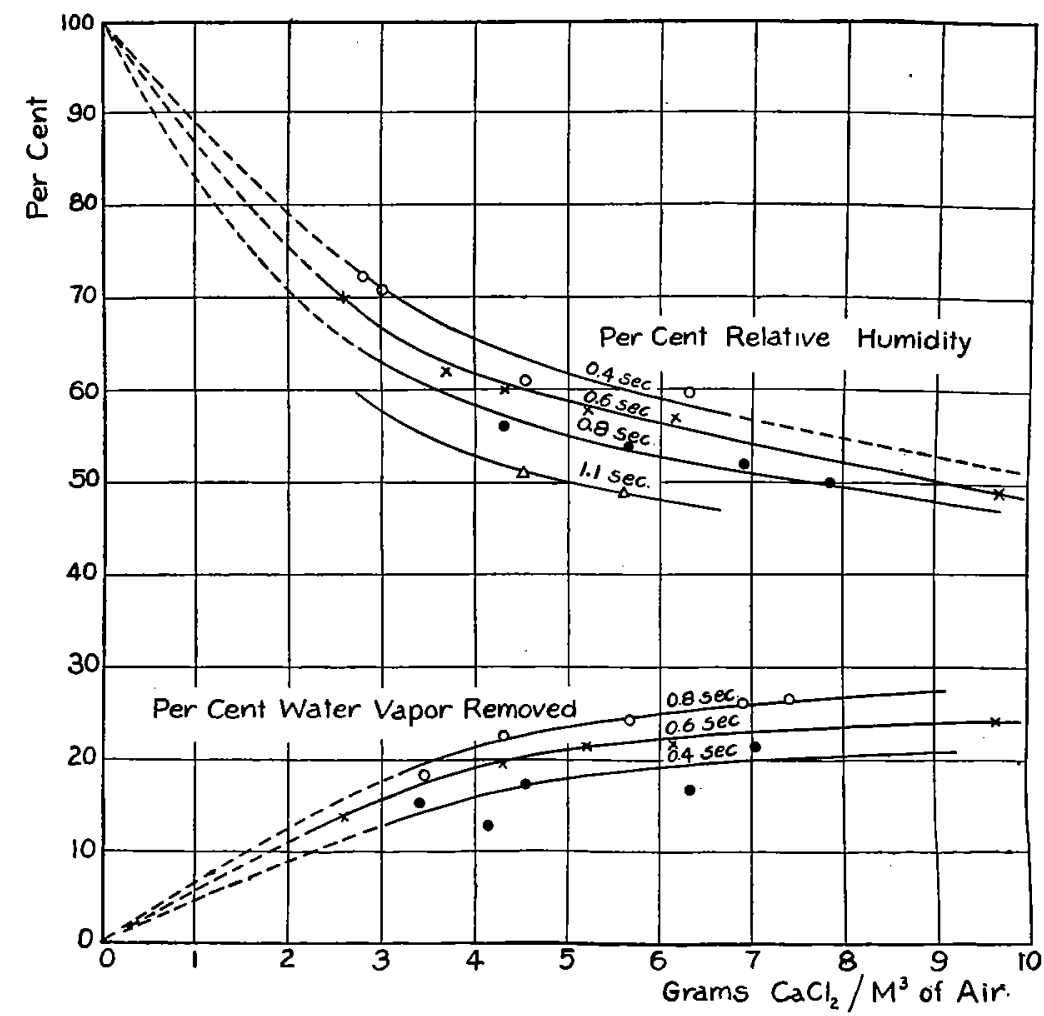

FrG. 3.-Experimental results obtained with the model unit showing both per cent relative humidity of the exit air and the percentage of water vapor removed as functions of the powder rate, expressed in grams of $\mathrm{CaCl}_{2} / \mathrm{m}^{3}$ of air. There are curves for various action times. The measurements were made with ambient air temperatures of 18 to $21^{\circ} \mathrm{C}$ and with relative humidities greater than $95 \%$. These curves should be compared with those in Fig. 2.

the most striking characteristics of the curves of Figs. 3 and 4 is their decrease in slope as the powder rate is increased. The reason for this saturation effect is that as the amount of powder is increased the individual particles act in progressively drier air. It is also evident from the curves that the relative humidity reduction changes very slowly with action time. Thus, with a powder rate of $5 \mathrm{~g} / \mathrm{m}^{3}$ doubling the action time from 0.4 to 0.8 second decreases the exit relative humidity only from 62 to 55 per cent. The explanation of this effect is that during the additional action time the vapor density $D$ (Eq. (I)) in the space surrounding each calcium chloride particle is relatively small due to the reduced relative humidity. At the same time the vapor density $D_{0}$ at the surface of each particle is relatively greater due to the dilution of the drop. Hence, the effective vapor density 
difference $\left(D-D_{0}\right)$, and therefore the water vapor condensation rate, becomes greatly reduced as the action time increases. Another contributing factor is that as the initially dry particles collect water vapor they tend to become covered with a layer of calcium chloride solution, the concentration of which depends upon the rate at which the dry core material dissolves. It is evident from the curves in Fig. 3 that about half of the observed relative humidity reduction was due to the air temperature rise. This heating is caused principally by the release of the heat of condensation of the water vapor and partly by the heats of solution and dilution of the calcium chloride particles.

Comparison of the experimental curves with the similar computed curves in Fig. 2 reveals a fairly good agreement. The important difference between the two sets of data is that the experimental curves indicate a more pronounced saturation effect as the powder rate is increased. This is probably owing to the fact that the assumption of uniform 40 micron particles, made for the purposes of the computations, did not properly take into account the size distribution of the particles of the powder used in the tests. Another probable contributing factor is the non-homogeneity of the particles arising from their finite rates of solution.

A consideration of the above experimental results, in the light of the known requirements for successful fog dissipation, led to the tentative conclusion that it should be feasible to

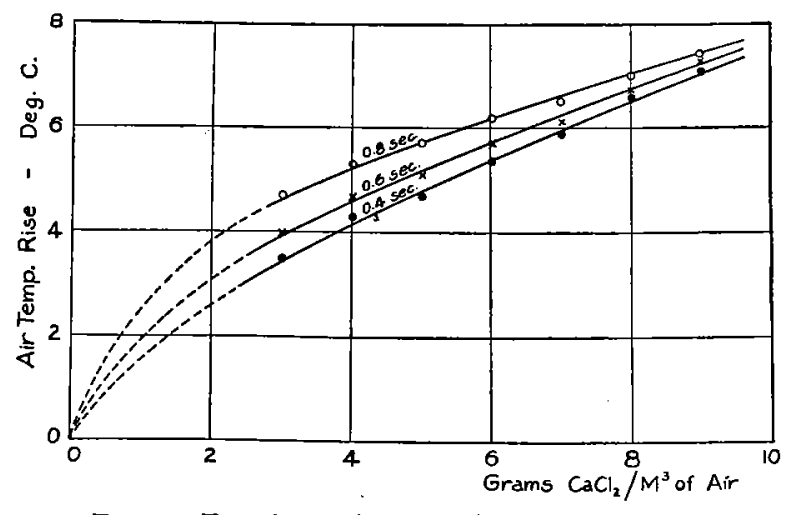

FIG. 4.- Experimental results obtained with the working model of the improved fog dissipator, showing the temperature rise of the exit air as a function of the powder rate, expressed in grams of $\mathrm{CaCl}_{2} / \mathrm{m}^{3}$ of air. There are curves for various action times. The ambient air temperature ranged between 18 and $21^{\circ} \mathrm{C}$ and the relative humidity was greater than $95 \%$. construct and operate a full-sized fog dissipator of the type proposed. Assuming the utilization of calcium chloride powder similar to that employed in the model tests, it was decided from the curves in Fig. 3 that the full-sized unit would probably be operated so as to give an exit relative humidity of about $50 \%$. It appeared that this could be done with a reasonable quantity of powder and a sufficiently short action time. From the capacity requirements it was known that a unit of useful size would have to be operated with an air velocity of at least I 5 meters per second in order to keep its physical dimensions within reasonable bounds.

\section{Investigation of Eliminator Characteristics}

Because of its fundamental importance the eliminator problem received careful consideration. There seemed to be little doubt that, if the requirements could be properly met, it would be preferable to use an eliminator of more or less conventional form. To be satisfactory the eliminator should have good collection efficiency at air velocities of $\mathrm{I} 5$ or more meters per second and at the same time it should have the least possible air resistance consistent with a high efficiency. Its construction should be such that the solution would drain freely from the collecting surfaces and the air resistance should be independent of the degree of wetting. Moreover, the separator elements should be reasonably easy to fabricate and assemble, and the completed unit should be as compact and as light as possible. 
To facilitate a study of the problem, apparatus was arranged for measuring the efficiency and air resistance of a number of small models of different types of eliminators. Efficiency tests were made with atomized droplets of calcium chloride solution, the concentration of which was adjusted so that the drops would be in vapor pressure equilibrium with the atmosphere. Eliminator efficiencies were determined by dividing the volume of solution collected in a given time by the volume sprayed. Air velocities and static pressure drops were determined from pitot tube measurements.

Among the more or less conventional types of eliminators tested were a $60^{\circ}$ bentplate unit having projecting lips, a unit comprising ten No. 4 mesh wire screens and a unit consisting of a number of staggered rows of vertical round rods $\mathrm{I} .3 \mathrm{~cm}$ in diameter. With all of these units it was found that after a certain definite critical velocity was ex-

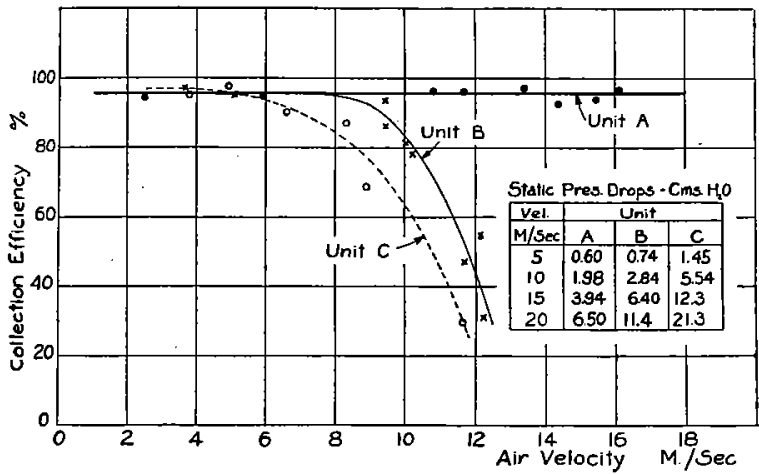

Fig. 5.-Experimental data on three types of eliminators showing collection efficiencies as functions of air velocity in meters/sec. The tabulated values give static pressure drops at various air velocities. All of the test units were mounted in ducts about $15 \times 20 \mathrm{cms}$ in cross-section. Unit $A$ is of the streamlined type and comprises six rows of vertical streamlined bars having a cross-section with a length of $3.3 \mathrm{cms}$ and a width of $1.3 \mathrm{cms}$. The members of each row are spaced with $2.5 \mathrm{cms}$ between centers. Successive rows are staggered and spaced about $5 \mathrm{cms}$ apart. Unit B consists simply of ten No. 4 mesh galvanized wire screens mounted normal to the duct axis and spaced about $5 \mathrm{cms}$ apart. Unit $C$ is of the $60^{\circ}$ bent plate typc comprising to vertical plates, each having five bends the last two of which have small projecting lips. The distance between bends, measured along the plate, is $5 \mathrm{cms}$. The plate separation, measured at right angles to the duct axis, is about $2 \mathrm{cms}$. On the basis of these test results Unit A was selected for use in the proposed full-sized fog dissipator.

struction tends to eliminate unnecessary and ineffective large-scale turbulence.

Tests made on models of streamlined eliminators yielded results entirely in accord with expectations. The typical test data reproduced in Fig. 5 clearly indicate the outstanding superiority of the streamlined unit which has a practically constant efficiency throughout the range of velocities from 2.0 to I 8 meters per second. The efficiencies of the other types tested, on the other hand, are so low at velocities above approximately Io meters per second that they are practically useless, particularly in view of their relatively large air resistances. -

Upon completion of the investigation just described, a larger model of a streamlined eliminator was constructed for confirmative tests in the model fog dissipator (Fig. 1 ). 
This unit replaced the screen type eliminator ${ }^{3}$ used in the early tests with that apparatus. The larger streamlined unit consisted of six rows of vertical bars having cross-sectional widths and lengths of about 2.5 and $7.5 \mathrm{~cm}$ respectively, the members of each row being spaced $5 \mathrm{~cm}$ between centers. Successive rows were staggered and were spaced about IO $\mathrm{cm}$ apart. The collection-efficiency versus air-velocity characteristic of this unit was determined using spray from a bank of low pressure hollow-cone nozzles. The sprayed drops were considerably larger than the atomized drops used in the tests with the small eliminators, resulting in a somewhat higher collection efficiency, but otherwise the performance was similar to that of the small streamlined unit. It was therefore concluded that this type of eliminator is satisfactory for use in the proposed full-sized fog dissipation apparatus.

\section{Distribution of the Dried Atr}

The method of fog dissipation described in this section purposes to cause a sufficient reduction in relative humidity in a fraction of the air to be cleared so that, after mixing this dried air with the remaining volume of fog, the relative humidity of the air mass as a whole will be reduced enough to cause rapid evaporation of the fog drops therein. On the basis of the results obtained with the spray type fog dissipator, it was decided that in order to maintain a clearing of useful size in fogs accompanied by winds having velocities of from 3 to $7 \mathrm{~m} / \mathrm{sec}$, water vapor must be condensed at a rate which produces a $90 \%$ relative humidity in a minimum of 2000 cubic meters of fog per second. Furthermore, it is known to be necessary for the dehumidified air to be so distributed that the resulting clearing will have an initial width of at least 30 or $4 \circ$ meters, as otherwise its extent down-wind will be insufficient owing to the limiting effects of atmospheric turbulence. Although specific information is not available on the dissipation of fogs accompanied by little or no wind, it is believed that in such cases treatment of the same minimum quantity of air is desirable since, with proper distribution, a somewhat larger clearing can thereby be formed.

The experimental results of the model tests previously described indicate that the relative humidity of the air passing through the proposed apparatus cannot be reduced below approximately $50 \%$ without using an excessive quantity of calcium chloride. Obviously, however, the required relative humidity of $90 \%$ can be produced in $2000 \mathrm{~m}^{3}$ of fog per second by discharging from the drying unit $400 \mathrm{~m}^{3}$ of air per second having a relative humidity of $50 \%$, and uniformly mixing this air with four times its volume of fog. This must be done so as to form a satisfactory clearing under all wind conditions. In fog accompanied by wind of moderate velocity $(3$ to $7 \mathrm{~m} / \mathrm{sec}$ ), the dried air should be uniformly distributed over a cross-section which is perpendicular to the wind direction and at least 30 or 40 meters wide. In practically calm fog, uniform mixing must be effected throughout the volume of the desired clearing.

The distribution problem could be most directly solved by discharging the dried air from numerous appropriately spaced exit ports. In fact, on the basis of present knowledge, this distribution method is believed to be preferable in cases where it can be used. However, with mobile apparatus such an arrangement is obviously more or less impracticable and, if it is possible, it would be preferable to distribute the dehumidified air from a single large opening.

\footnotetext{
${ }^{3}$ Similar to "unit (B)," data on which appear in Fig. 5
} 
Owing to the complexity of the turbulent atmospheric mixing phenomena involved, the distribution problem cannot be satisfactorily dealt with by purely theoretical methods. Therefore, in order to determine the practicability of distributing all of the dried air from a single large opening, certain experimental investigations were undertaken with the aid of a large blower consisting of a 330 horsepower radial aircraft engine, fitted with a 2.7 meter tractor propeller. This unit was mounted 3 meters above the ground on a special truck. Some of the later tests were made after the propeller had been enclosed in a tunnel about 6 meters long. During most of the tests the axis of the propeller was inclined upward at an angle of about 17 degrees. The engine and propeller were designed for the propulsion of an airplane and had a rather low efficiency as a blower. The maximum discharge rate was about $\mathrm{I} 20 \mathrm{~m}^{3} / \mathrm{sec}$ at a velocity of $20 \mathrm{~m} / \mathrm{sec}$. The distribution of air effected by this unit, under various wind conditions, was studied by introducing into the air stream either small pieces of paper or a water spray. The lateral extent was readily determined by direct observation and the maximum vertical extent was measured with the aid of a theodolite.

In relatively calm air it was found that the blower would distribute the test material over a total distance of about 150 meters, with a maximum elevation of about 30 meters. With the blower operating in a fixed position, the lateral spread was only about 20 meters. When the blower was aimed directly into wind having a velocity of $5 \mathrm{~m} / \mathrm{sec}$, the observed distribution was about 40 meters laterally and 25 meters vertically. With the discharge perpendicular to wind of the same velocity, the distribution was found to be only 20 meters cross-wind and 20 meters vertically. With wind, the widest possible lateral distribution was obtained when the blower discharge was rapidly oscillated about the average down-wind direction, through a total included angle of I 80 degrees.

Unfortunately, the tests described were not sufficiently comprehensive to permit final conclusions as to the best possible methods for satisfactorily distributing the dried air from the proposed fog dissipator under all probable wind conditions. However, from the test results it appears that, with a discharge of $400 \mathrm{~m}^{3} / \mathrm{sec}$ at a velocity of $20 \mathrm{~m} / \mathrm{sec}$ or more, satisfactory distribution can always be effected from a single large opening if proper precautions are taken. To avoid excessive vertical distribution of the dried air, which cannot compensate fully for insufficient horizontal distribution, it is probably not desirable for the discharge of the proposed dissipator to have a vertical inclination, as did the test blower. When dissipating fog on the scale assumed the initial vertical distribution of the dried air should probably never exceed ro meters, owing to the natural tendency of the cleared air to diffuse upward.

In order to insure adequate distribution in calm air it would be necessary either to rotate the unit continuously or to move it in a direction perpendicular to the blower discharge. In fogs accompanied by steady winds satisfactory distribution can probably be obtained by operating the unit with the discharge aimed either into the wind, or downwind, and at the same time oscillating it rapidly with sufficient amplitude to give the clearing an initial cross-sectional area such that the volume of air carried through it by the wind does not exceed $2000 \mathrm{~m}^{3} / \mathrm{sec}$.

\section{Design Considerations}

The three most important factors to be considered in the design of fog dissipators of the proposed type are the amount of hygroscopic material required, the physical dimensions of the unit and the power requirements of the blower. The relative importance of 
these factors depends on the particular application. In the case of a fixed installation, where space restrictions might not be severe, it would probably be desirable to keep both the material and power requirements at a minimum. In a mobile unit, on the other hand, it is likely to be more important to keep the size and weight at a minimum. To furnish some concrete idea of the order of magnitude of the principal design factors, two units will now be considered, one fixed and the other mobile. A discharge of $400 \mathrm{~m}^{3} / \mathrm{sec}$ and an outlet relative humidity of $50 \%$ will be assumed in each case.

For the fixed installation a discharge velocity of $20 \mathrm{~m} / \mathrm{sec}$ will be specified. A maximum action time of about one second is reasonable for this application. From Fig. 3 it is seen that this corresponds to about $5.5 \mathrm{~g}$ of powder per cubic meter of air. Roughly $27.5 \%$ of the water vapor will be condensed and, according to data in Fig. 4, the air will be heated about $6.5^{\circ} \mathrm{C}$. The air velocity in the tunnel may be selected to give a suitable crosssection and length but it should not be less than about one-half the discharge velocity, since a lower value would necessitate the use of too long a converging section. If a value of $12 \mathrm{~m} / \mathrm{sec}$ is chosen the cross-section will be about $33 \mathrm{~m}^{2}$ and in order to provide an action time of I second the length from the powder discharge port to the eliminator will be I 2 meters. The probable overall length will be is meters. The powder rate will be $2.2 \mathrm{~kg} / \mathrm{sec}$. To provide the kinetic energy of the discharged air and to overcome losses at the eliminator and other losses due to friction, there will be required 3 Ig theoretical air horsepower. If the efficiency of the blower is $70 \%$ the engine must have $456 \mathrm{hp}$.

It is believed that at airports fixed installations might advantageously be made underground, probably with a system of distributed discharge ports at or near the ground level. One interesting possible application is on naval aircraft carriers. The entire unit could be located beneath the forward end of the flying deck and the dried air could be discharged vertically upward through multiple flush gratings. However, for this application a larger unit would be required because of the high speed at which aircraft carriers are operated.

As pointed out above, in the case of a mobile unit it is desirable to keep the physical dimensions and gross weight at a minimum. This means that the shortest possible action time and the highest possible air velocity should be used. An action time of about 0.5 second seems appropriate, requiring a powder rate of $\mathrm{I} O \mathrm{~g} / \mathrm{m}^{3}$ to produce the desired exit relative humidity of $50 \%$. Roughly $22.5 \%$ of the water vapor will be condensed, and the air temperature will be raised about $7.8^{\circ} \mathrm{C}$. The air velocity is determined by making a suitable balance between the cross-section and the length, with the added restriction that the required blower power should not exceed a value which can be obtained readily in a single unit. A velocity of $15 \mathrm{~m} / \mathrm{sec}$ is suitable, requiring a cross-section of about 27 square meters and a length from the powder discharge ports to the eliminator of 7.5 meters. The overall length of the unit would be about I 2.5 meters. On the assumption of a $30 \mathrm{~m} / \mathrm{sec}$ outlet velocity the total air power required is $565 \mathrm{hp}$ or an engine power of $807 \mathrm{hp}$ at a fan efficiency of $70 \%$. The powder rate is evidently $4 \mathrm{~kg} / \mathrm{sec}$. It has been estimated that a unit of this size would have a gross weight of about I 5 tons including the calcium chloride powder. This is not an unreasonable weight for a mobile unit as many modern motor trucks have greater gross weights. In cases where the size or weight of such a unit would be objectionable, or where other features inherent in multiple units are desirable, it is evidently possible to use two or more smaller units. This would have the further advantage of simplifying the problem of distributing the dried air. ${ }^{4}$

${ }^{4}$ The principal dimensions and operating conditions of the proposed fixed and mobile units are tabulated under Fig. I for convenient comparison. 
Since the spent hygroscopic material is collected by the eliminator there is evidently a possibility of reclaiming it. If powdered calcium chloride is used, as has been assumed throughout this paper, the spent material will be in the form of a calcium chloride solution which can be reconverted to powder only by a rather involved process. The use of a finely atomized solution in place of the powder would permit the immediate re-use of the material after an evaporation process. If calcium chloride solution were used it would be desirable for it to have a high concentration (of the order of $70 \%$ by weight) requiring a relatively high solution temperature. The hot solution could be taken directly from an evaporator.

It is also possible that corrosive, hygroscopic liquids such as sulfuric acid and solutions of the strong alkalies might be used if the quantity escaping through the eliminator could be reduced to a negligible amount. Unfortunately, the fine atomization of liquids requires a considerable amount of power and this might prove to be the limiting condition although larger drops could be employed by increasing the amount sprayed.

Another substance which might possibly be utilized in the proposed apparatus is powdered calcium oxide (quicklime). As pointed out in the first section of this paper, calcium oxide reacts with atmospheric carbon dioxide and water vapor, releasing a large quantity of heat. If this substance were used in the present method, most of the relative humidity reduction would be due to heating of the air, but by supplying more than enough lime to remove all of the atmospheric carbon dioxide an appreciable amount of water vapor could also be removed. Owing to the lack of specific information on the rate at which the reactions would proceed with particles of practical size, it is impossible to state whether or not the method is feasible. However, assuming that the calcium oxide could be utilized with an efficiency of $50 \%$, only $4.8 \mathrm{~kg} / \mathrm{sec}$ would be required to reduce the relative humidity from saturation at $20^{\circ} \mathrm{C}$. to $50 \%$ in $400 \mathrm{~m}^{3}$ of air per second. ${ }^{5} \mathrm{By}$ using extremely fine powder in sufficient quantities it might be practicable to reduce the relative humidity of the discharged air to values appreciably under $50 \%$. This cannot be done economically with calcium chloride, for reasons which have been explained.

Obviously, the general method of fog dissipation discussed in this section can be modified so that the necessary relative humidity reduction is affected solely by heating the air. Instead of using hygroscopic material to condense atmospheric water vapor, or calcium oxide as suggested in the preceding paragraph, heat can be applied to the air as it passes through the drier by any convenient method, such as by burning fuel oil directly in it. The requirements and possibilities of dissipating fog by heated air blasts were noted in the first section of the paper.

\section{Conclusion}

It is desired to emphasize the fact that large volumes of fog, such as over an entire airport or harbor, cannot be cleared by the drier method or any other method which involves the evaporation of the fog drops because of the energy and distribution requirements. A relatively small unit with the capacity assumed in this paper, capable of discharging $400 \mathrm{~m}^{3}$ of air per second at a relative humidity of $50 \%$ should maintain clear a space about 40 meters wide, Io to 20 meters high, ${ }^{6}$ and from 600 to I000 meters long, at

5 This computation is based on reaction equations (3) and (4) in the first section of the paper. Removal of 0.553 $\mathrm{g} / \mathrm{m}^{3}$ of $\mathrm{CO}_{2}$ (normal atmospheric content) and $1.69 \mathrm{~g} / \mathrm{m}^{3}$ of water vapor is assumed. The calculated accompanying temperature rise is $10.5^{\circ} \mathrm{C}$.

6 Although the initial cross-section of the clearing would measure only 40 by Io meters, the maximum width and height would be appreciably greater, owing to the atmospheric mixing effects described in section III. 
a wind velocity of 5 meters per second. At lower velocities, or in calm air, the cleared space would be considerably larger.

The difficulties and dangers of landing aircraft in fog with present-day radio aids increase rapidly as the ground is approached. It is believed that a relatively small clearing, such as can be readily formed by the type of fog dissipator described, would largely eliminate the hazards now existing in the final stage of a "blind landing" in fog. In the same way the method might find application to the docking of ships.

It is believed that the practicability of the type of fog dissipator discussed is indicated by the results contained in this paper. The most important feature of the method is that the hygroscopic material is confined almost entirely within the apparatus. It has the further advantage that a unit of this type may be operated in all reasonable winds and may be mobile. Notwithstanding its relatively large size, a mobile unit would constitute a less serious obstruction on an airport than did the original spray type fog dissipator.

In conclusion the authors wish to express their appreciation to Mr. Thomas Tedesco, the Fog Research Mechanician, whose keen interest, skill and ingenuity in carrying out his part of the construction and operation of the many pieces of experimental apparatus contributed greatly to the success of the research program. The authors are also indebted to Messrs. Bert Hill and W. H. Sparrow of Round Hill Airport who assisted greatly in the mounting and maintenance of the Wright engine used in the experimental blower unit. 